\title{
Detection of repeating earthquakes and their application in characterizing slow fault slip
}

Naoki Uchida(i)

\begin{abstract}
Repeating earthquakes (repeaters) that rupture the same fault area (patch) are interpreted to be caused by repeated accumulation and release of stress on the seismic patch in a creeping area. This relationship between repeaters with fault creep can be exploited for tracking the fault creep (slow slip) based on the repeaters' activity. In other words, the repeaters can be used as creepmeters embedded on a fault. To do this, it is fundamentally important to select earthquakes that definitely re-rupture in the same area. The selections are usually done based on waveform similarity or hypocenter location. In hypocenter-location based detection, the precision of the relative location compared with the dimension of earthquake sources is critical for confirming the co-location of the source area. On the other hand, waveform-similarity-based detection needs to use appropriate parameters including high enough frequency components to distinguish neighboring sources. Inter-event timing (recurrence interval) and/or the duration of a sequence's activity are good diagnostic features for finding appropriate detection parameters and eliminating non-repeating events, which are important because an inappropriate selection leads to including triggered sequences that do not re-rupture the same area. Repeaters provide an independent estimation of creep from geodetic data and such estimations are mostly in good agreement when both kinds of data are available. Repeater data are especially useful in the deeper part of strike-slip faults and in near-trench areas of subduction zones where geodetic data's resolution is usually limited. The repeaters also have an advantage with geodetic data analysis because they are not contaminated by viscoelastic deformation or poroelastic rebound which are prominent postseismic process for large earthquakes and occur outside of faults. On the other hand, the disadvantages of repeater analysis include their uneven spatial distribution and the uncertainty of the estimates of slip amount requiring a scaling relationship between earthquake size and slip. There are considerable variations in the inferred slip amounts from different relationships. Applications of repeater analysis illuminate the spatial distribution of interplate stable slip, after slip, and spontaneous and cyclic slow slip events that represent important components of interplate slip processes in addition to major earthquakes.
\end{abstract}

Keywords: Repeating earthquake, Interplate slip, Fault creep, Aseismic slip

\section{Introduction}

It is well known that earthquakes that occur in close proximity have similar waveforms (e.g., Omori 1905; McEvilly and Casaday 1967; Hamaguchi and Hasegawa 1975; Poupinet et al. 1984; Geller and Mueller 1980). These similar earthquakes include those located very near to each other (neighboring) and actually co-located events (sharing the same slip area). Both co-located and

Correspondence: naoki.uchida.b6@tohoku.ac.jp

Graduate School of Science, Tohoku University, 6-6 Aramaki Aza Aoba, Sendai, Miyagi 980-8578, Japan

(c) The Author(s). 2019 Open Access This article is distributed under the terms of the Creative Commons Attribution 4.0 International License (http://creativecommons.org/licenses/by/4.0/), which permits unrestricted use, distribution, and reproduction in any medium, provided you give appropriate credit to the original author(s) and the source, provide a link to the Creative Commons license, and indicate if changes were made. 
Nadeau and McEvilly 1999; Igarashi et al. 2003) and estimating various properties of slow slip including postseismic slip (e.g., Uchida et al. 2004; Hayward and Bostock 2017), spontaneous slow slip episodes (e.g., Nadeau and McEvilly 2004; Uchida et al. 2016b) and preseismic slip (e.g., Kato et al. 2012). These observations of slow slip suggest they are essential fault deformation process together with regular earthquakes. Therefore, it has become increasingly important to clarify the optimal method of selecting repeating earthquakes and obtaining reliable measurements of slow slip from repeating earthquakes.

In this article, I first review the general procedure for detecting repeating earthquakes. Then, I discuss appropriate parameters for selecting repeating earthquakes based on waveform similarity which suggest the importance of selecting an appropriate frequency range. I also discuss the triggered sequences and their characteristics in event intervals. Next, I review the procedure for quantifying the slow slip associated with repeating sequences, including the scaling relationship between earthquake magnitude and slip. Lastly, I will provide an overview of the application of repeating earthquakes for estimating slow fault slip in various tectonic settings and discuss how they compare with estimates from geodetic data.

\section{Review \\ Model of repeating earthquakes and their relation with slow slip}

Repeating earthquakes are interpreted as representing repeated ruptures of a fault patch that are driven to failure by loading from aseismic creep on the surrounding fault surface. Therefore, the seismic slip of repeating earthquakes can be related to the fault creep in the surrounding area during the interseismic period. Figure 1 shows the general concept of how repeating earthquake analysis can be used to estimate fault creep. The cumulative slip of repeating earthquakes can be assumed to be equal to the creep on the surrounding fault area of the repeater patch. Observations of repeating earthquakes provide a useful estimate of slow slip based on their activity pattern.

\section{Detection method}

An important condition for repeating earthquakes that can be used to estimate the amount of slow fault slip is whether the earthquakes represent repetitive rupture on

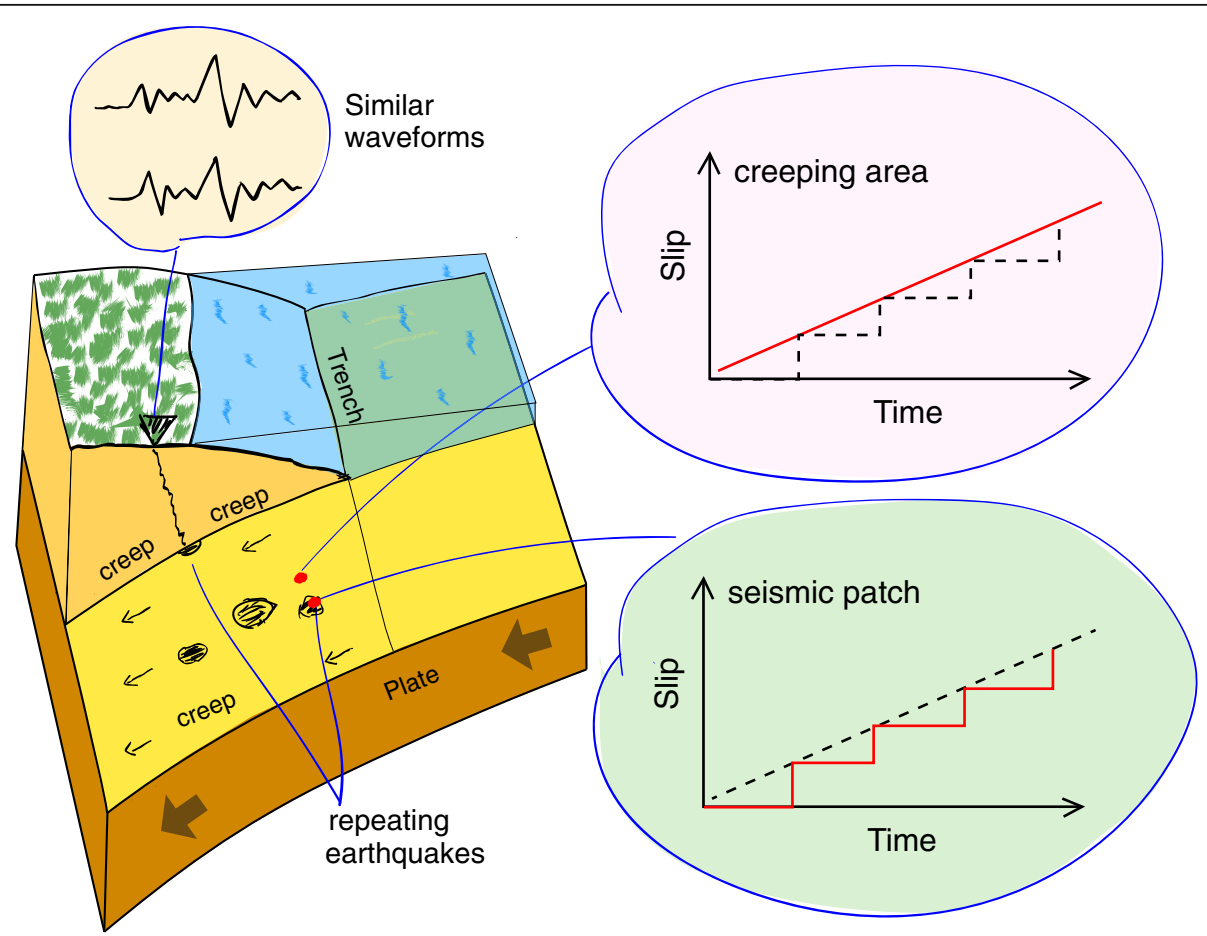

Fig. 1 Schematic model of the environment where repeating earthquakes occur in a subduction zone. The repeating earthquakes occur on a seismic patch (black spots) in the creeping area of the plate boundary. They produce similar waveforms when observed by the same station (left top) because the seismic patch is loaded by creep in the surrounding area and repeat rupture at the same place. The creeping area (slip shown in red in the right top panel) and repeating earthquake patch (slip shown in red in the right bottom panel) undergo almost the same long-term cumulative slip because they are located on neighboring plate boundaries. The dashed line shows slip at neighboring area (seismic patch for creeping area and vice versa). Please note the patch for the repeating earthquake may have slip in the interseismic period (Beeler et al. 2001) but the relationship between the slip at the creeping area and the slip at patch for repeating earthquakes holds in that case too 
a common patch (being co-located) or not. An example of co-located earthquakes (repeaters) and their waveforms are shown in Fig. 2. Their location estimates show overlapping source areas (Fig. 2a) and their waveforms are very similar (Fig. 2c). Both source areas and waveform characteristics can be used to detect repeating earthquakes, as detailed below.

\section{Detection of small repeating earthquakes from hypocenter locations}

Determining hypocenters is a straightforward way to confirm overlapping source areas and to detect repeating earthquakes. The precision of relative hypocenter locations, however, should be high enough compared with the earthquake source sizes to confirm the co-location. Most previous works have utilized waveform-based differential time to obtain precise relative earthquake locations
(Ellsworth 1995; Waldhauser and Schaff 2008; Yu 2013). Repeating earthquakes have similar waveforms, and thus their time differentials can be obtained accurately from waveform cross-spectra or waveform cross-correlations (Waldhauser and Ellsworth 2000) (Table 1).

The double-difference method (Waldhauser and Ellsworth 2000) is one popular method of obtaining precise locations with an uncertainty of as little as a few meters (Waldhauser et al. 2004). Other methods used to estimate relative locations include a master-event algorithm which is used by $\mathrm{Yu}$ (2013). Conditions for obtaining precise locations include good clocks (timing accuracy) and a sufficient number of data (stations) with good spatial distribution. Chen et al. (2008) used a double-difference method based on S-P time for estimating location when working on the data with clock uncertainties.

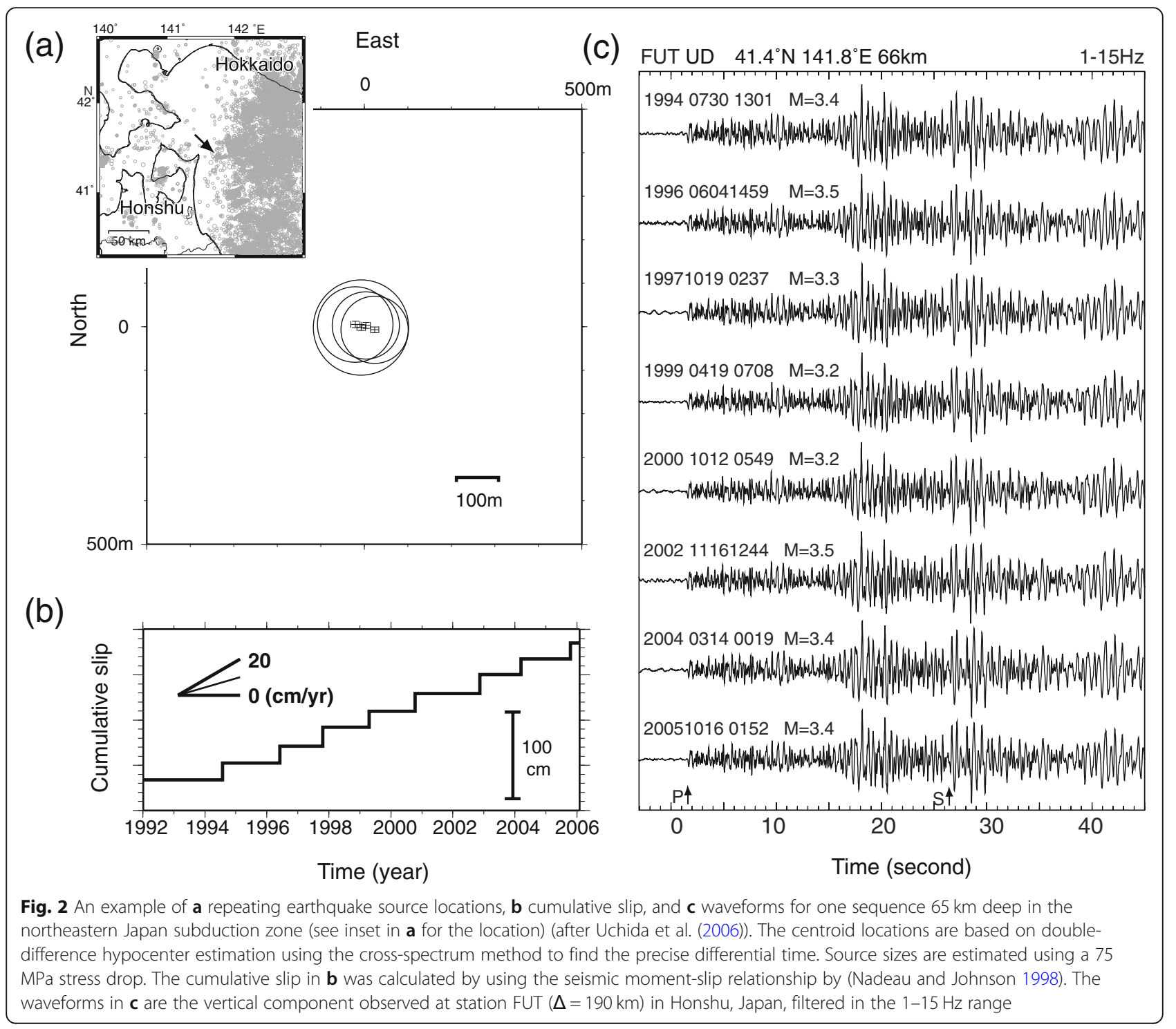


Table 1 Comparison of repeating earthquake selection and slip estimation methods for selected papers

\begin{tabular}{|c|c|c|c|c|c|c|c|}
\hline References & Region & Detection method & Time window & $\begin{array}{l}\text { Frequency } \\
\text { range }\end{array}$ & M range & $\begin{array}{l}\text { Slip } \\
\text { scaling }\end{array}$ & Comments \\
\hline $\begin{array}{l}\text { Nadeau and } \\
\text { McEvilly (1999) }\end{array}$ & $\begin{array}{l}\text { Parkfield, } \\
\text { California }\end{array}$ & $C C \geqq 0.98$ & - & - & $\begin{array}{l}\text { N/A (M- } 1 \text { to } 5 \\
\text { used) }\end{array}$ & $N \& J$ & \\
\hline $\begin{array}{l}\text { Igarashi et al. } \\
\text { (2003); Uchida } \\
\text { et al. (2003) }\end{array}$ & $\begin{array}{l}\text { Tohoku, } \\
\text { Japan }\end{array}$ & $C C \geqq 0.95$ & $40 \mathrm{~s}$ & $1-4 \mathrm{hz}$ & $\begin{array}{l}4.6 \geqq M>=3 \\
\text { (Igarashi et al.), } \\
M \geqq 2 \text { (Uchida et } \\
\text { al.) }\end{array}$ & $N \& J$ & \\
\hline $\begin{array}{l}\text { Nadeau and } \\
\text { McEvilly (2004) }\end{array}$ & $\begin{array}{l}\text { San Andreas } \\
\text { fault }\end{array}$ & $\begin{array}{l}\text { CC, Coh, visual } \\
\text { inspection, relocation, } \\
\text { arrival time analysis }\end{array}$ & - & - & $3.4 \geqq M \geqq-0.4$ & $\begin{array}{l}\text { N\&J } \\
\text { (constants } \\
\text { different) }\end{array}$ & \\
\hline $\begin{array}{l}\text { Matsubara et } \\
\text { al. (2005) }\end{array}$ & $\begin{array}{l}\text { Hokkaido, } \\
\text { Japan }\end{array}$ & $C C \geqq 0.95$ & $\begin{array}{l}40 \mathrm{~s} \text { or until } 5 \mathrm{~s} \\
\text { after } \mathrm{S} \text { arrival }\end{array}$ & $1-8 \mathrm{~Hz}$ & $M \geqq 2$ & $N \& J$ & \\
\hline $\begin{array}{l}\text { Kimura et al. } \\
\text { (2006) }\end{array}$ & Kanto, Japan & $C C \geqq 0.95$ & $\begin{array}{l}2 \mathrm{~s} \text { before } P \text { arrival } \\
\text { to } 5 \mathrm{~s} \text { after } \mathrm{S} \text { arrival }\end{array}$ & $1-20 \mathrm{~Hz}$ & $4.56 \geqq M \geqq 2.0$ & $N \& J$ & \\
\hline $\begin{array}{l}\text { Uchida et al. } \\
(2006,2009 a, \\
\text { b, 2011) }\end{array}$ & $\begin{array}{l}\text { Miyagi-oki, } \\
\text { Tohoku } \\
\text { Japan }\end{array}$ & Coh $\geqq 0.95$ & $40 \mathrm{~s}$ & $1-8 \mathrm{~Hz}$ & $4.8 \geqq M \geqq 2.5$ & $N \& J$ & $\begin{array}{l}\text { Upper range of } M \text { is } \\
\text { from Uchida et al. } \\
(2009 a, 2009 b)\end{array}$ \\
\hline $\begin{array}{l}\text { Rau et al. } \\
\text { (2007) }\end{array}$ & $\begin{array}{l}\text { Longitudinal } \\
\text { valley fault, } \\
\text { Taiwan }\end{array}$ & $\begin{array}{l}\text { waveform (CC) and } \\
\text { differential S-P time }\end{array}$ & $\begin{array}{l}10.5 \mathrm{~s}(\mathrm{CC}), 2.5 \mathrm{~s} \\
\text { (differential S-P) }\end{array}$ & $2-18 \mathrm{~Hz}$ & $4.6 \geqq M \geqq 2.1$ & $N \& J$ & $\begin{array}{l}\text { CC has several } \\
\text { thresholds }\end{array}$ \\
\hline $\begin{array}{l}\text { Chen et al. } \\
\text { (2008) }\end{array}$ & $\begin{array}{l}\text { Chihshang } \\
\text { fault, Taiwan }\end{array}$ & $\begin{array}{l}\text { CC and differential S- } \\
\text { P time }\end{array}$ & $\begin{array}{l}10.5 \mathrm{~s}(\mathrm{CC}), 2.5 \mathrm{~s} \\
\text { (differential S-P) }\end{array}$ & $2-18 \mathrm{~Hz}$ & $3.7 \geqq M \geqq 1.9$ & $N \& J$ & $\begin{array}{l}\text { CC has several } \\
\text { thresholds }\end{array}$ \\
\hline $\begin{array}{l}\text { Lengliné and } \\
\text { Marsan (2009) }\end{array}$ & $\begin{array}{l}\text { Parkfield, } \\
\text { California }\end{array}$ & $\begin{array}{l}\text { Coh } \geqq 0.9 \text { and location } \\
\text { (overlapping }>70 \% \text { ) }\end{array}$ & $1.28 \mathrm{~s}$ (P wave) & $1.5-18 \mathrm{~Hz}$ & $M \geqq 1.2$ & $N \& J$ & $\begin{array}{l}3 \mathrm{MPa} \text { stress drop, } \\
\text { magnitude } \\
\text { difference }<0.2\end{array}$ \\
\hline Igarashi (2010) & Japan & $C C \geqq 0.95$ & $\begin{array}{l}\mathrm{P} \text { arrival to } 3 \mathrm{~s} \text { after } \\
\mathrm{S} \text { arrival }\end{array}$ & $\begin{array}{l}1-4,2-8 \text {, and } \\
4-16 \mathrm{~Hz}\end{array}$ & $M \geqq 2$ & $N \& J$ & $\begin{array}{l}\text { Frequency range } \\
\text { depends on } \\
\text { magnitude. }\end{array}$ \\
\hline Li et al. (2011) & $\begin{array}{l}\text { Longmen } \\
\text { Shan fault, } \\
\text { China }\end{array}$ & $\begin{array}{l}\mathrm{CC} \geqq 0.9 \text { and internal } \\
\text { consistency of time } \\
\text { picking }\end{array}$ & $\begin{array}{l}1 \mathrm{~s} \text { before a } P \text { arrival } \\
\text { to } 5 \mathrm{~s} \text { after } \mathrm{S} \text { arrival }\end{array}$ & $1-10 \mathrm{~Hz}$ & $2.8 \geqq M \geqq 0.9$ & Crack & $\begin{array}{l}\text { Average recurrence } \\
\text { interval of }>100 \\
\text { days }\end{array}$ \\
\hline $\begin{array}{l}\text { Yamashita et } \\
\text { al. (2012) }\end{array}$ & $\begin{array}{l}\text { Hyuganada, } \\
\text { southwest } \\
\text { Japan }\end{array}$ & $C C \geqq 0.95$ & $40 \mathrm{~s}$ & $2-8 \mathrm{~Hz}$ & $4.3 \geqq M \geqq 2.5$ & $N \& J$ & $\begin{array}{l}\text { Duration }<3 \text { years } \\
\text { removed, focal } \\
\text { mechanism checked }\end{array}$ \\
\hline $\begin{array}{l}\text { Kato et al. } \\
\text { (2012) }\end{array}$ & $\begin{array}{l}\text { Tohoku, } \\
\text { Japan }\end{array}$ & $\begin{array}{l}\text { Matched filter } \\
\text { detection and } \\
\mathrm{CC} \geqq 0.95\end{array}$ & $\begin{array}{l}\text { P-wave onset to } 4 \mathrm{~s} \\
\text { after direct S-wave } \\
\text { arrival. }\end{array}$ & $\begin{array}{l}1-4,2-8 \text {, and } \\
4-16 \mathrm{~Hz}\end{array}$ & & $N \& J$ & $\begin{array}{l}\text { Frequency range } \\
\text { depends on } \\
\text { magnitude }\end{array}$ \\
\hline $\begin{array}{l}\text { Uchida et al. } \\
(2013,2016 a, b)\end{array}$ & $\begin{array}{l}\text { Tohoku, } \\
\text { Japan }\end{array}$ & $\begin{array}{l}\text { Coh } \geqq 0.95(1-8 \mathrm{~Hz}) \\
\text { or Coh } \geqq 0.8(1 / 2-2 \\
\text { fc) }\end{array}$ & $40 \mathrm{~s}$ & $\begin{array}{l}1-8 \mathrm{~Hz} \text { or } \\
\text { around the } \\
\text { corner } \\
\text { frequency (fc) }\end{array}$ & $M \geqq 2.5$ & $N \& J$ & \\
\hline Yu et al. (2013) & $\begin{array}{l}\text { Tonga- } \\
\text { Kermadec- } \\
\text { Vanuatu }\end{array}$ & $\mathrm{CCC} \geqq 0.8$ & $30 \mathrm{~s}$ & $0.8-2.0 \mathrm{~Hz}$ & $5.7 \geqq M \geqq 4.7$ & $N \& J$ & \\
\hline $\begin{array}{l}\text { Taira et al. } \\
\text { (2014) }\end{array}$ & $\begin{array}{l}\text { San Juan } \\
\text { Bautista, San } \\
\text { Andreas fault }\end{array}$ & CC and Coh $\geqq 0.95$ & $\begin{array}{l}51.2 \mathrm{~s}(M \geqq 2), 5.12 \mathrm{~s} \\
(M \leqq 2.5)\end{array}$ & $\begin{array}{l}1-8 \mathrm{~Hz}(\mathrm{M} \geqq 2) \\
8-24 \mathrm{~Hz} \\
(\mathrm{M} \leqq 2.5)\end{array}$ & $3.5 \geqq M \geqq 0.5$ & $N \& J$ & \\
\hline $\begin{array}{l}\text { Meng et al. } \\
(2015)\end{array}$ & $\begin{array}{l}\text { Northern } \\
\text { Chile }\end{array}$ & $C C \geqq 0.95$ & $\begin{array}{l}3 \mathrm{~s} \text { before a } \mathrm{P} \text { arrival } \\
\text { to } 10 \mathrm{~s} \text { after } \mathrm{S} \text { arrival }\end{array}$ & $\begin{array}{l}1-8 \mathrm{~Hz}(3> \\
\mathrm{Mw} \geqq 2.5) \\
1-4 \mathrm{~Hz} \\
(\mathrm{Mw} \geqq 3)\end{array}$ & $4.8 \geqq M w \geqq 2.9$ & $N \& J$ & \\
\hline $\begin{array}{l}\text { Mavrommatis } \\
\text { et al. (2015) }\end{array}$ & $\begin{array}{l}\text { Tohoku, } \\
\text { Japan }\end{array}$ & $\begin{array}{l}\mathrm{Co} \geqq 0.95(1-8 \mathrm{~Hz}) \text { or } \\
\mathrm{Coh} \geqq 0.8(1 / 2-2 \mathrm{fc})\end{array}$ & $40 \mathrm{~s}$ & $\begin{array}{l}1-8 \mathrm{~Hz} \text { or } \\
\text { around the } \\
\text { corner } \\
\text { frequency (fc) }\end{array}$ & $M \geqq 2.5$ & Beeler & $\begin{array}{l}\text { Event selected by } \\
M \text {, variation in } \mathrm{M} \\
\text { and duration }\end{array}$ \\
\hline $\begin{array}{l}\text { Gardonio et al. } \\
\text { (2015) }\end{array}$ & Kanto, Japan & $\begin{array}{l}\text { Coh } \geqq 0.90 \text { and } \\
\text { location (overlapping }\end{array}$ & $5.12 \mathrm{~s}$ & $1.5-8 \mathrm{~Hz}$ & $M \geqq 1.0$ & $\begin{array}{l}\text { No slip } \\
\text { estimate }\end{array}$ & $\begin{array}{l}\text { Magnitude } \\
\text { difference }<0.5\end{array}$ \\
\hline
\end{tabular}


Table 1 Comparison of repeating earthquake selection and slip estimation methods for selected papers (Continued)

\begin{tabular}{|c|c|c|c|c|c|c|c|}
\hline References & Region & Detection method & Time window & $\begin{array}{l}\text { Frequency } \\
\text { range }\end{array}$ & M range & $\begin{array}{l}\text { Slip } \\
\text { scaling }\end{array}$ & Comments \\
\hline $\begin{array}{l}\text { Dominguez et } \\
\text { al. (2016) }\end{array}$ & $\begin{array}{l}\text { Middle } \\
\text { America } \\
\text { Trench, } \\
\text { Mexico }\end{array}$ & $\begin{array}{l}\text { CC and } \\
\text { Coh } \geqq 0.90 \text { (threshold } \\
\text { A), CC, and } \\
\text { Coh } \geqq 0.95 \text { (B) }\end{array}$ & $25.6 \mathrm{~s}$ & $1-8 \mathrm{~Hz}$ & $\begin{array}{l}4.5 \geqq M \geqq 2.5(\mathrm{~A}) \\
4.5 \geqq M \geqq 3.1(\mathrm{~B})\end{array}$ & N\&J & \\
\hline $\begin{array}{l}\text { Schmittbuhl et } \\
\text { al. (2016) }\end{array}$ & $\begin{array}{l}\text { Marmara } \\
\text { fault, Turkey }\end{array}$ & $C C \geqq 0.9$ & $15 s$ & $1-10 \mathrm{~Hz}$ & $2.5>M>1$ & Crack & \\
\hline $\begin{array}{l}\text { Yao et al. } \\
\text { (2017) }\end{array}$ & $\begin{array}{l}\text { Nicoya } \\
\text { Peninsula, } \\
\text { Costa Rica }\end{array}$ & $\begin{array}{l}\text { Matched filter } \\
\text { method (mean } \\
C C \geqq 0.9 \text { ) }\end{array}$ & $6 s$ & - & $3.2 \geqq M \geqq 0.5$ & Crack & $\begin{array}{l}\text { Template events } \\
\text { have } \mathrm{S} / \mathrm{N} \geqq 5 \text { for } \\
\text { more than } 9 \text { traces }\end{array}$ \\
\hline $\begin{array}{l}\text { Materna et al. } \\
\text { 2018) }\end{array}$ & $\begin{array}{l}\text { Mendocino } \\
\text { Triple } \\
\text { Junction }\end{array}$ & Coh $\geqq 0.97$ & $\begin{array}{l}30 \text { s before the } P \\
\text { arrival to } 20 \mathrm{~s} \text { after } \\
\text { the } P \text { wave arrival }\end{array}$ & $\begin{array}{l}0.5-15 \mathrm{~Hz}(\mathrm{~S} / \\
\mathrm{N} \geqq 5)\end{array}$ & $3 \geqq M \geqq 1.5$ & $N \& J$ & \\
\hline
\end{tabular}

CC waveform cross-correlation, Coh waveform coherence, N\&J Nadeau and Johnson (1998)'s scaling relationship (Eq. (1)), Beeler: Beeler et al. (2001)'s relationship (Eq. (2)), Crack crack model (Eq. (3) or others)

After obtaining repeaters' relative locations, the source size is used to evaluate how they overlap. The source size of repeaters can be estimated from the corner frequency of their waveforms (e.g., Uchida et al. 2012; Imanishi et al. 2004) or using waveform inversion (e.g., Okada et al. 2003; Dreger et al. 2007; Kim et al. 2016). These studies use spectrum ratios or empirical Green's functions to take into account attenuation and other path effects. However, these techniques are generally complicated and too time-consuming, if we want to utilize them for many possible repeater candidates. A popular method for obtaining source size is to assume a stress drop based on regional studies and use the relationship between seismic moment $\left(M_{0}\right)$ and source radius (r) (Eshelby 1957),

$$
r=\left((7 / 16)\left(M_{0} / \Delta \sigma\right)\right)^{1 / 3} .
$$

Figure 2a shows an example of double-difference relocations in which a stress drop of $75 \mathrm{MPa}$ was used for the source size. The seismic moment used here was estimated by the formulas of Hanks and Kanamori (1979):

$$
\log \left(M_{0}\right)=1.5 M+9.1
$$

Note that the assuming low stress drops results in a large slip radius and apparent overlapping may occur for more distant events. The stress drops used in several studies are listed in Table 1 . The minimum source overlap used as a condition for repeating earthquakes in previous studies range from 50 to $70 \%$ in the previous studies (Lengliné and Marsan 2009; Waldhauser and Ellsworth 2002; Gardonio et al. 2015).

\section{Detection of small repeating earthquakes from waveform similarities}

We can select repeating earthquakes by taking advantage of the idea that earthquakes that ruptured the same source area with the same rupture process should have exactly the same waveforms if the medium and recording system has not changed. The similar waveforms at a particular station indicate small inter-event distances and similar focal mechanisms (Menke 1999; Nakahara 2004). This is a less exact way to confirm co-location but represents a powerful and relatively robust procedure if we choose the analysis parameters carefully. The waveform-similarity based detection is popular than the detection from hypocenter locations (see "Detection method" section column in Table 1) most probably due to their relatively smaller requirements for the amount and quality of data (e.g., the number of stations, station distribution, and timing accuracy of station clocks). This method needs only one station that is available throughout the analysis period, although using multiple stations provides a more robust detection.

\section{Quantification of waveform similarity between earthquakes}

Two major methods for evaluating the waveform similarity are cross-correlation analysis and cross-spectral analysis of waveform coherence (Poupinet et al. 1984) (Table 1). The waveform cross-correlation coefficient is defined as $C(\tau)=\frac{1}{N} \sum_{t=1}^{N} f_{x}(t) f_{y}(t+\tau)$, where $f_{x}$ and $f_{y}$ are two time series (e.g., waveforms) of earthquakes $x$ and $y$ with $N$ discrete samples and $\tau$ is the lag time. We can obtain the maximum cross correlation coefficient (CC) by varying the lag time. Waveform coherence is defined as $\operatorname{coh}(\omega)=\sqrt{\frac{\left|S_{x y}(\omega)\right|^{2}}{S_{x x}(\omega) S_{y y}(\omega)}}$. Here, $S_{x y}(\omega)$ is the cross spectrum between earthquakes $x$ and $y$ that is calculated from the Fourier transform of the original waveforms $\left(f_{x}\right.$ and $f_{y}$ ). We usually use the average of coherence (Coh) for a certain frequency range. The cross-correlation and cross-spectrum methods are very similar, other than that the frequency range is set before the calculations for evaluating similarity are done in cross-correlation while selection is done after the calculations in the 
cross-spectrum method (Schaff et al. 2004). The co-location of overlapping sources is judged from the values of $\mathrm{CC}$ or Coh for a pair of waveforms recorded at the same station having the same or equivalent recording system throughout the study period (Fig. 1). Note that changes in the recording system and/or the characteristics of the seismometers used may result in apparent changes in waveforms if the responses are not corrected. The maximum values of $\mathrm{CC}$ and Coh are 1 and a large $\mathrm{CC}$ or Coh value (usually 0.95 or higher are chosen) suggests nearly identical waveforms.

To reduce computation time, evaluations of $\mathrm{CC}$ or Coh are usually done for event pairs within a certain inter-event distance based on the routine hypocenter locations of the events. The summation of hypocenter location uncertainties for the pair is a good basis for determining a search volume because co-located events may be mislocated at points that are separated by their uncertainties. Search radii in previous studies have been $80 \mathrm{~km}$ in the Tonga-Kermadec-Vanuatu

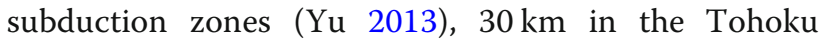
and Mendocino triple junctions (Igarashi et al. 2003; Materna et al. 2018), but smaller values may be appropriate in more densely instrumented areas. Most studies calculate $\mathrm{CC}$ or $\mathrm{Coh}$ for individual stations that are averaged later (Table 1). The matched filter method (Gibbons and Ringdal 2006; Shelly et al. 2007), which scans continuous waveforms and utilizes both waveform similarity and consistency of travel times between stations has also been used to detect repeaters (Yao et al. 2017).

\section{Formation of repeater sequence from pairs of repeaters}

Once repeating earthquake pairs are defined from hypocenter locations and/or waveform similarities, a repeating earthquake sequence can be formed from the pairs. A simple equivalence class algorithm (Press et al. 2007) is used in many studies (Igarashi et al. 2003; Uchida et al. 2003; Peng and Ben-Zion 2005; Materna et al. 2018; Meng et al. 2015; Yao et al. 2017; Kimura et al. 2006; Nadeau et al. 1995). The algorithm groups pairs that share the same events into the same repeater sequence. In other words, if event pairs $(\mathrm{A}, \mathrm{B})$ and $(\mathrm{B}, \mathrm{C})$ are repeater pairs, events $A, B$, and $C$ are grouped into one sequence regardless of the similarity/overlapping between $\mathrm{A}$ and $\mathrm{C}$. Another method employed to combine pairs is a clustering algorithm based on the unweighted pair group method with arithmetic mean (Romesburg 2004; Hayward and Bostock 2017). This grouping produces sequences in which the average $\mathrm{CC} / \mathrm{Coh}$ of each member event of a sequence with all other members in the sequence is greater than the desired CC/Coh threshold.

\section{Parameters for better selection of repeating earthquakes from waveform similarities}

Waveform similarity provides less direct evidence for overlapping sources than hypocenter colocation and it requires careful analysis to obtain a reliable repeater catalog. In this section, I discuss finding better selection parameters including an optimal choice of time windows and lower and upper limits of analysis frequency.

\section{Analysis time window}

In calculating waveform similarity, the length of the sample time window is an important factor that affects the value of CC or Coh. Time windows are usually set to contain both $\mathrm{P}$ and $\mathrm{S}$ phases to assure the same P-S time and thus the same hypocentral distance (e.g., Uchida et al. 2003; Igarashi et al. 2003). A longer time window reduces the possibility of high cross-correlation or coherence by chance but may contain low signal-to-noise ratio coda waves. Some studies use a variable window length, depending on the S-wave arrival time (e.g., Kimura et al. 2006; Taira et al. 2014; Meng et al. 2015), but the others use a fixed value that is long enough for the target earthquakes (e.g., Matsubara et al. 2005; Uchida et al. 2003; Igarashi et al. 2003) (Table 1). The signal-to-noise ratio ( $\mathrm{S} / \mathrm{N}$ ratio) is also considered in some cases (Materna et al. 2018).

\section{Lower limit of analysis frequency range}

Selection of proper frequency range is important not only to reduce the effect of noise but also to make the $\mathrm{CC} / \mathrm{Coh}$ value more informative for judging whether the sources overlap or not. In general, waveforms at too low frequencies do not have enough resolution to distinguish between nearby non-overlapping and overlapping events.

One method for finding a suitable lower limit of the frequency range is to consider the "quarter wavelength rule" (Geller and Mueller 1980) for waveform similarity. Similar seismograms at a given frequency suggest that their first-Fresnel zones (the prolate ellipsoidal space between two points) overlap (Geller and Mueller 1980; Ellsworth 1995). In other words, two events located within a quarter wavelength cannot be separated based on waveform similarity even if they do not overlap (Geller and Mueller 1980). Thus, the use of high-frequency waveform data whose quarter wavelengths are smaller than their rupture dimension is necessary to reduce the possibility of non-overlapping events. Taking this into account, when the frequency $(f)$ condition that has overlapping events with the same source size can be distinguishable is $f \geq v_{s} / 4 r$, where $v_{s}$ is shear wave speed and $r$ is the source radius. Since the source size usually depends on the earthquake size (magnitude, seismic moment), the optimal lower limit of the frequency range 
also depends on earthquake size. The recommended minimum frequency to be included in the repeater analysis is shown by the gray line in Fig. 3a. Here, the source sizes (radii $r$ ) of the events are calculated from magnitudes $(M)$ assuming the circular crack model and stress drops $(\Delta \sigma)$ of $10 \mathrm{MPa}$, using Eq. (2) by Hanks and Kanamori (1979) and Eq. (1) by Eshelby (1957).

The effect of the choice of the lower limit for the analysis frequency range can be examined from inter-event coherences whose source location and sizes are precisely estimated. The off-Kamaishi earthquake is one such example (Fig. 4a) and Fig. 5 demonstrates how coherence changes with inter-event distance for pairs of earthquakes in the earthquake cluster that contain repeater sequences. Here, the distances are normalized by the fault radius (inter-event distances are divided by the sum of the fault radii of the two earthquakes). The centroids and source sizes used to calculate the normalized distance are respectively constrained by the double-difference method using waveform cross-spectra and spectral ratio analysis and have uncertainties of less than $\sim 30 \mathrm{~m}$ and $\sim 6 \%$, respectively (Uchida et al. 2012). For the coherence calculations, the time window is $40 \mathrm{~s}$ and two frequency ranges extend with half to twice the corner frequency for the smaller event of each pair (Fig. 5a) and a fixed frequency range of $1-2 \mathrm{~Hz}$ (Fig. 5b) are selected for the analysis. The corner frequencies are calculated from the following formula by Sato and Hirasawa (1973)

$$
f_{0}=C v / 2 \pi r
$$

and Eq. (1), where $v$ is the phase velocity $(4.4 \mathrm{~km} / \mathrm{s})$ and $C$ is a constant. We assumed $C$ to be 1.9 and the stress drop to be $10 \mathrm{MPa}$. Please note that the frequency range $(1-2 \mathrm{~Hz})$ is below the frequency range appropriate for selecting repeaters for most of the analyzed events of magnitudes 2.4-3.6 (Fig. 3a).

The relationship between inter-event distance and coherence shows that coherence decreases significantly if the pairs do not overlap (normalized distance $>1$ ) for analysis of the frequency range near the corner frequency (Fig. 5a). It also shows that the radius ratio (the source radius of the smaller event divided by that of the larger event) also affects the value of coherence. The coherence threshold (0.8) used in (Uchida and Matsuzawa 2013) corresponds to a minimum radius ratio of about 0.6 . On the other hand, for the low-frequency range (1$2 \mathrm{~Hz}$, Fig. 5b), coherence does not drop significantly for non-overlapping events (normalized distance $>1$ ) and the coherence at each station (small white circles) is sometimes large (>0.95) for non-overlapping events.
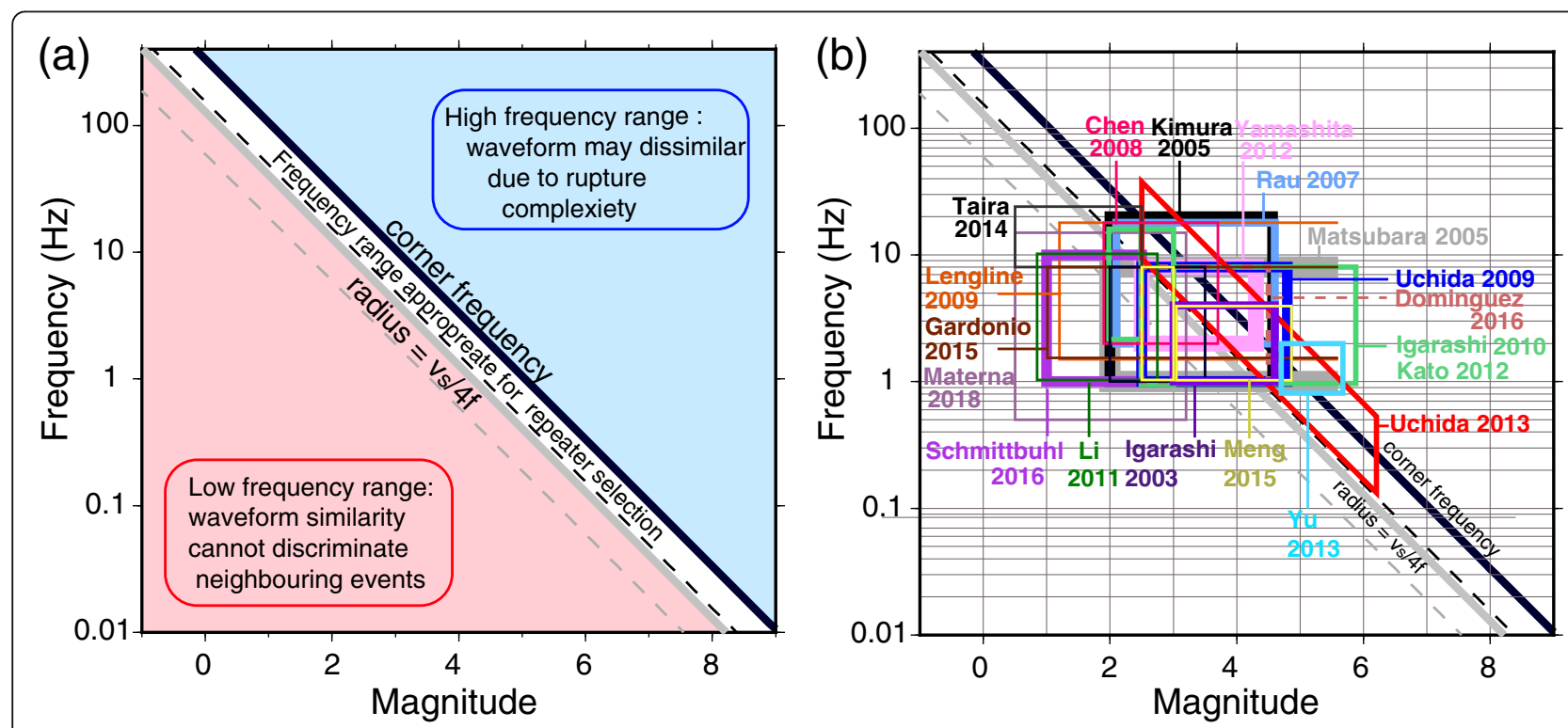

Fig. $\mathbf{3}$ a Frequency and magnitude ranges suitable for repeater detection from waveform similarity based on considerations of source size and $\mathbf{b}$ ranges used in previous studies. Black and gray lines respectively show the corner frequency and the condition where the resolution is equal to the fault radius for a $10 \mathrm{MPa}$ stress drop. Dashed black and gray lines are the same but for a $1 \mathrm{MPa}$ stress drop. Frequencies larger than the corner frequency (blue area) are considered to be inappropriate because the rupture process, including the initiation point and propagation may affect waveforms' shape. Having the resolution lower than the fault radius (radius $\leq v_{s} / 4 f$ ) (red area) is also inappropriate because non-overlapping events can also have similar waveforms. In $\mathbf{b}$, frequency and magnitude ranges are plotted for the studies listed in Table 1. Note that only the first author and publication year are shown for each study and some studies used not only waveform similarity but also hypocenter location or other conditions to confirm repeaters. When the maximum size of detected earthquakes is not reported, the upper bounds of magnitude are not shown 

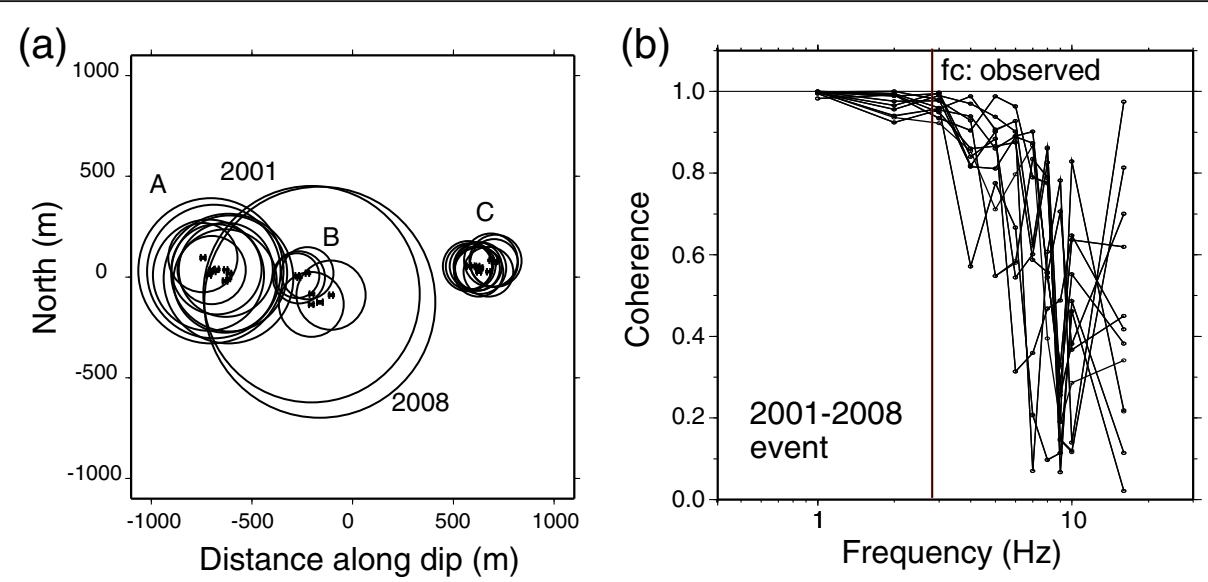

Fig. 4 a Slip area distribution in the off-Kamaishi earthquake cluster. Circle size denotes rupture dimension estimated from corner frequencies. Small bars show centroid location uncertainties. The labels 2001 and 2008 indicate M 4.8 repeating earthquakes in those years. The earthquakes labeled A-C are events with magnitudes 2.4-3.6 that occurred from 1995 to 2008. This figure is modified from Uchida et al. (2012). b Coherence dependence on frequency for the waveforms of the 2001 and 2008 M 4.8 repeating earthquakes for 11 stations. A time window of $40 \mathrm{~s}$ was used for the calculation. The vertical line shows the observed corner frequency from spectral ratio analysis (Uchida et al. 2012)

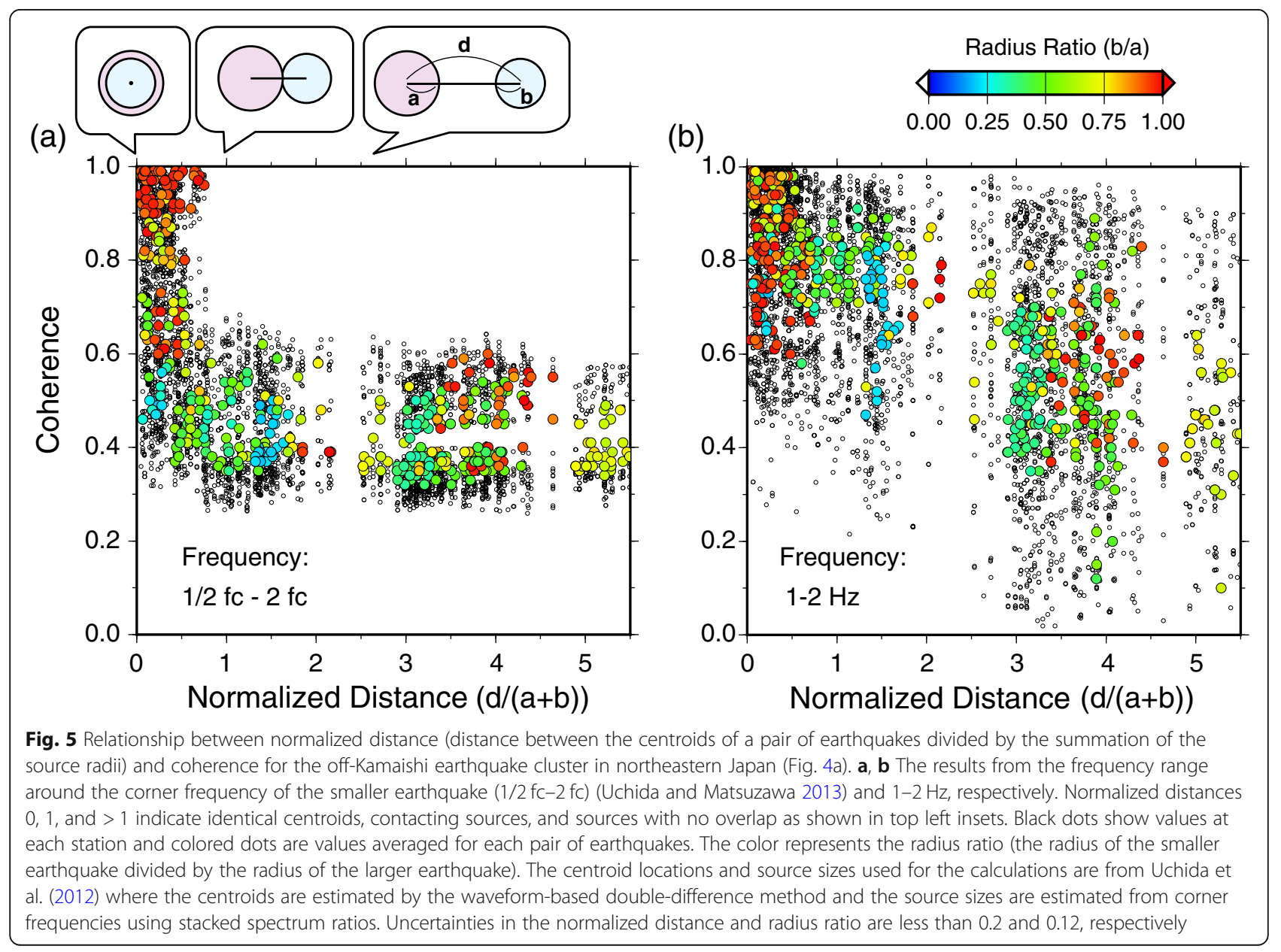


This suggests the possibility of selecting non-overlapping events in this frequency range even if a large coherence threshold is employed. In summary, an appropriate lower limit of the frequency range, which is dependent on the source size is important in selecting repeaters using waveform similarity.

\section{Upper limit of analysis frequency range}

The upper limit of the appropriate frequency range is considered to be related to the variability of the rupture process. The waveforms at high frequencies depend on rupture process variations within the slip area that can be different for repeating earthquakes even when sharing the same source area. In other words, the rupture initiation point (hypocenter) within a patch, slip directivity, etc. may change from event to event reflecting heterogeneous stress and strength within the patch (Kim et al. 2016; Shimamura et al. 2011; Bouchon 1997; Murray and Langbein 2006; Vidale et al. 1994) but this difference in dynamic process does not affect the total slip amount within the slip area. Figure $4 \mathrm{~b}$ shows the frequency dependence of coherence between the waveforms of the 2001 and $2008 M \sim 4.8$ off-Kamaishi repeating sequence (Fig. 4a). Although these sequences have almost completely overlapping source areas (Fig. 4a), the Coh at frequencies larger than the corner frequency significantly decrease from 1 . Such a decrease in coherence in frequency ranges higher than the corner frequency has also been reported for other repeating sequences (Hatakeyama et al. 2016). This means the use of frequency ranges lower than the corner frequency reduces the possibility of excluding events with different rupture patterns but co-located (repeating) events. The corner frequency dependence on earthquake magnitude (assuming the circular crack model) is shown in Fig. 3a. Here, I assumed 1 and $10 \mathrm{MPa}$ stress drops and used Eqs. 1, 2, and 3. This line can be used as the rough standards of the upper limit of analysis frequency range.

Most studies apply band-pass filtering before calculating cross-correlation or selecting a frequency range in evaluating coherence (Table 1) with a single frequency range. The frequency and magnitude ranges of detected repeating earthquakes are shown in Fig. $3 \mathrm{~b}$. Since the optimal frequency range for repeater selection from waveform similarity depends on the source size as discussed in this and previous sections, the use of a frequency range that depends on earthquake size (magnitude) will be better for selecting repeating earthquakes over a wide magnitude range. Igarashi (2010), Meng et al. (2015), and Taira et al. (2014) used multiple frequency ranges depending on earthquake magnitude (Fig. 3b). Uchida and Matsuzawa (2013) used frequency ranges relative to magnitude dependent corner frequencies (Fig. 3b). These studies succeeded in detecting repeaters over a relatively wide magnitude range (Table 1 , Fig. 3b).

\section{Evaluation of the repeater catalog and optimization of the repeater selection procedure}

Once repeaters are selected by any method, it is also important to evaluate the catalog and use it to optimize the repeater selection method. Since the present aim of selecting repeating earthquakes is to track the slip history at a particular point, it is both important to eliminate triggered sequences that are not overlapping events and avoid missing events.

\section{Triggered sequence in the repeater candidates}

Neighboring events are often triggered by each other (Rubin et al. 1999; Chen et al. 2013). Rubin et al. (1999) studied the microseismicity in the creeping section of the San Andreas Fault zone based on precise hypocenter locations. They showed that the second events of consecutive event pairs occurred outside the slip area of the first event assuming a $10 \mathrm{MPa}$ stress drop. This suggests a stress shadow at the slip area of the first event and triggering of the second event outside of the slip area of the first event (Fig. 6). However, it is sometimes difficult to distinguish neighboring events from co-located (repeating) events because they have both high waveform similarity and similar locations. For example, Bouchon et al. (2013) proposed repeated foreshock occurrences for the 1999 Izmit earthquake from the events' waveform similarity, but Ellsworth and Bulut (2018) suggested a triggered cascade of rupture for neighboring areas based on their estimate of precise location and slip areas.

In addition to location or waveform difference, temporal characteristics of triggered sequences can also be used to distinguish repeating earthquakes from the triggered sequence. Lengliné and Marsan (2009) clarified features of triggered sequences from repeater candidates selected based on waveform similarity and event overlapping ratios in Parkfield, CA (Fig. 7). They looked at the frequency distribution of recurrence intervals. The frequency distribution of events interval follows a power law decay with increasing event interval for events with intervals shorter than $10 \%$ of the sequence average. The decay rate of earthquake frequency with increasing interval is consistent with Omori's law and indicative of a triggering process. The spatial distribution of probably-triggered-events (events with interval times $10 \%$ or less of the average recurrence interval) is not spatially concentrated (i.e., the events are not co-located) (Fig. 7b) whereas events with interval times longer than $10 \%$ of the average show tightly concentrated event locations (Fig. 7c). This is consistent with the concept that it is difficult to reload a fault patch in a very small time interval, except for special conditions such as fast loading caused by postseismic deformation from large earthquakes, and we need careful evaluation for very short interval repeater candidates. 


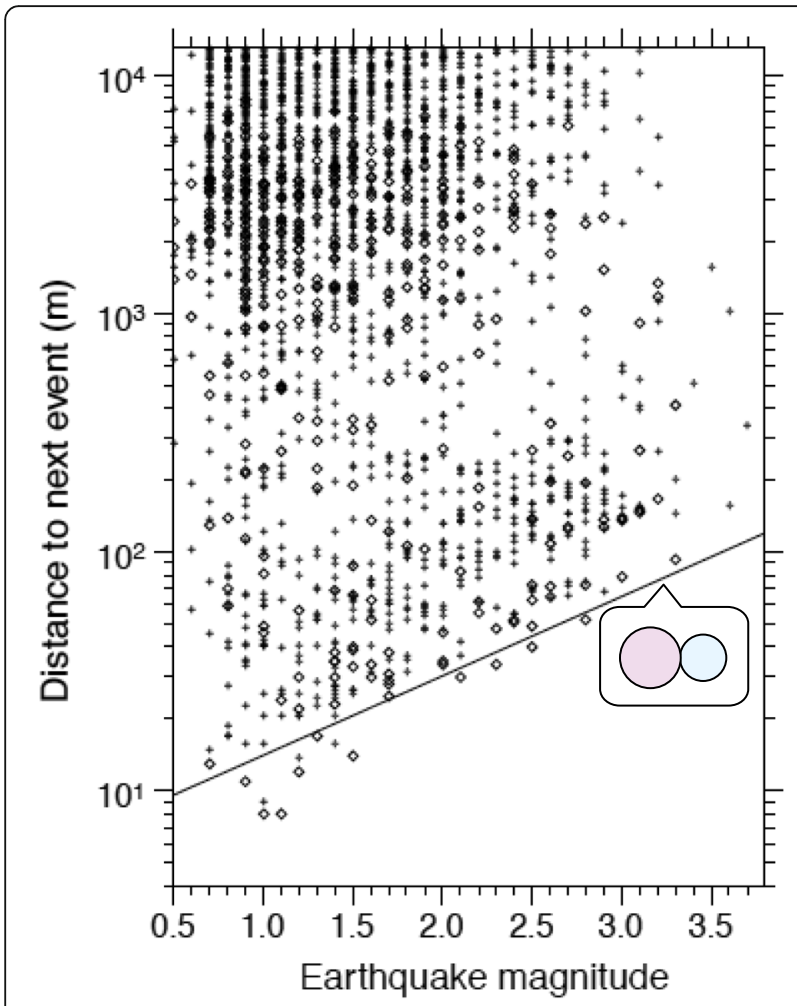

Fig. 6 Relationship between the magnitude of the first event and distance to the second earthquake for consecutive earthquakes in the creeping section of the San Andreas fault (after Rubin et al. 1999). Diamonds indicate that the vertical separation between the events exceeds the horizontal separation; crosses indicate the reverse. The diagonal line is the estimate of earthquake radius derived from the moment-magnitude relation of Abercrombie (1996), assuming a stress drop of $10 \mathrm{MPa}$

\section{Optimization of repeater selection}

As described in the previous section, an extremely short event interval can be a useful diagnostic feature for identifying triggered sequences among the sequences selected from waveform similarity and hypocenter locations, which have inevitable uncertainty in the detection (Lengliné and Marsan 2009; Materna et al. 2018; Li et al. 2011). We want to exclude triggered events that occur adjacent to each other and that often occurs over a short time interval. When setting the threshold for repeaters, the fraction of earthquakes with very short intervals (minutes to days) becomes unacceptably large if the selection criterion being used is too loose. Figure 8 shows an example of the frequency distributions of repeater candidates' recurrence intervals using two different coherence thresholds (0.8 and 0.95) for off-Tohoku earthquakes (Uchida and Matsuzawa 2013). The other detection conditions (calculation of coherence for a frequency range of $1-8 \mathrm{~Hz}$ and a time window of $40 \mathrm{~s}$ ) are the same. The figure shows that when an inadequately low coherence threshold of 0.8 is used, the fraction of very short earthquake intervals becomes large. The frequency of earthquake interval increases with decreasing time interval in the year scale (Fig. 8a), day scale (Fig. 8b), and minutes scale (not shown), suggesting that aftershock (triggered) sequences dominate for short-interval and relatively less-similar pairs. For the larger (preferred) coherence threshold (0.95), the frequency peaks at $\sim 1$ year and the frequency decreases when the interval is short, which probably reflects not enough time to load the same fault patch. The drastic change in the numbers of short-interval events brought about by increasing the coherence threshold suggests that most of the short-interval events have relatively low coherence and can be interpreted as triggered events

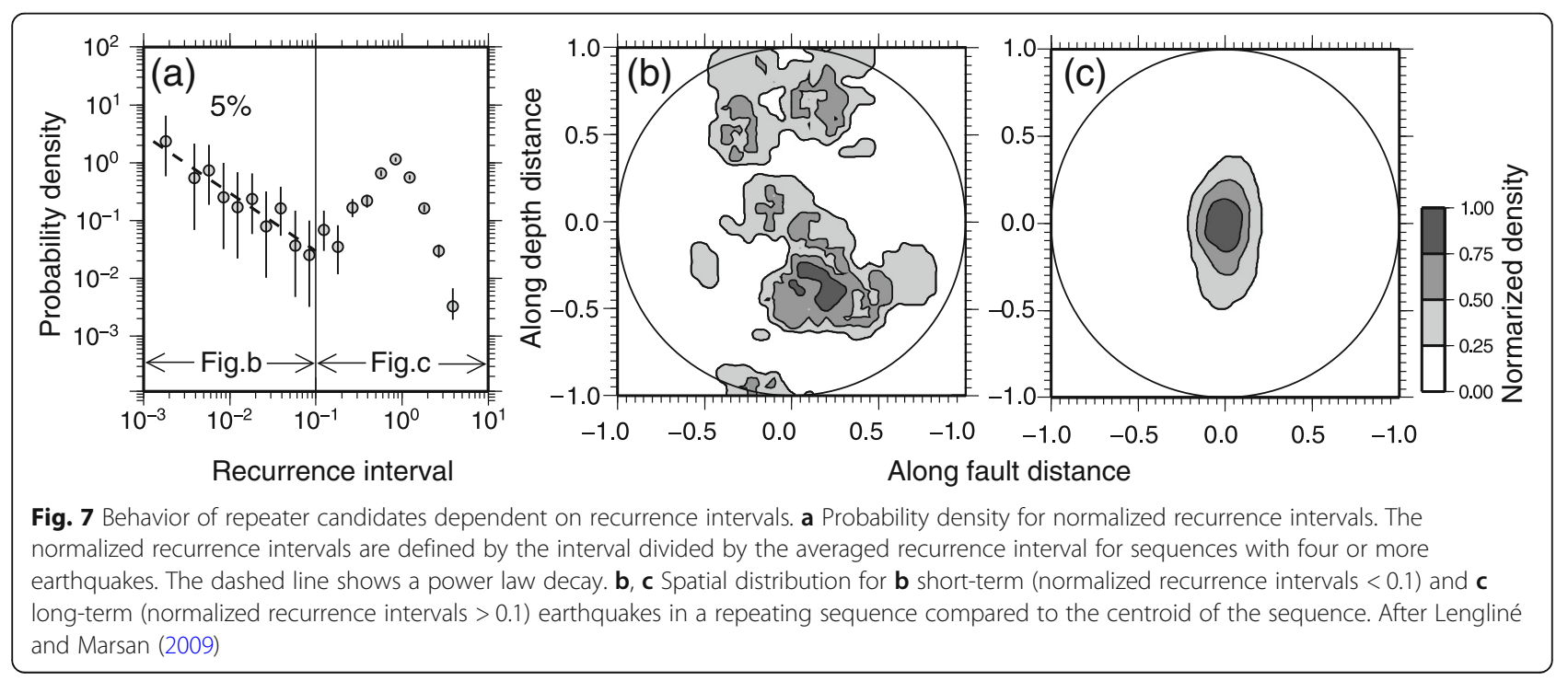


(a)

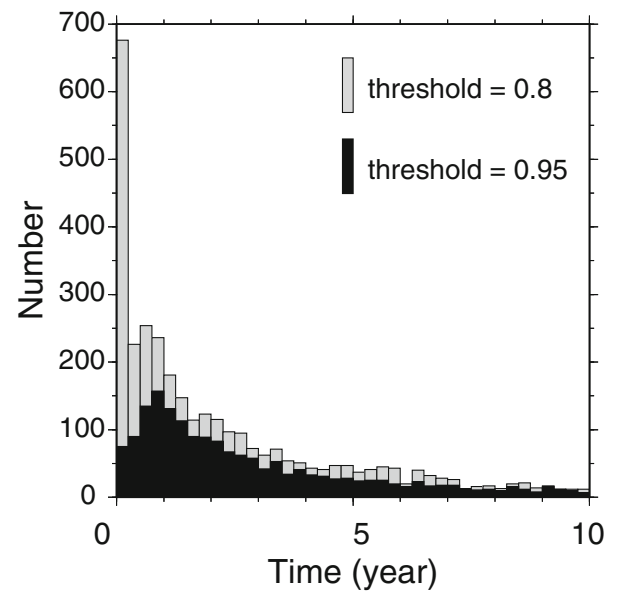

(b)

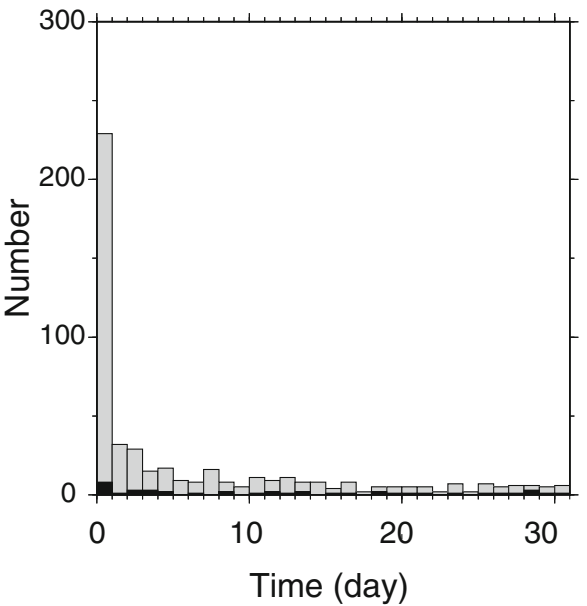

Fig. 8 Frequency distribution of the intervals of successive events using coherence thresholds of 0.8 (gray) and 0.95 (black). a 0 to 10 -year range in 0.25 year bins. $\mathbf{b} 0$ to 31 days in 1-day bins. The frequency range is $1-8 \mathrm{~Hz}$ and data used was from 1984 to 2006 offshore Tohoku

that are close but not co-located, although occasionally lower-coherence repeaters may occur after large earthquakes due to their slip dependency on pore pressure (Lengliné et al. 2014), fault healing (McLaskey et al. 2012), and loading rate (Hatakeyama et al. 2017).

The dependence of repeater catalogue on selection method is extensively examined in Lengliné and Marsan (2009) and Materna et al. (2018). The inclusion or exclusion of short-recurrence (probably triggered) sequences has a very large impact on which events are selected as repeaters, and inter-event timing is one of the most important features. For the estimation of slow slip from repeaters, the strict threshold can eliminate triggered sequence but may result in misdetection due to their uncertainty in location or waveform similarity decrease by noise. To this end, the inter-event time can be used to find appropriate repeater selection parameters. Another method to utilize inter-event time is to simply discard events with short inter-event times from repeater candidates to obtain continuous repeating earthquakes that are more likely reflect long-term fault slow slip. As an example of inter-event time filtering, Igarashi et al. (2003) used a 3-year duration threshold for selecting burst-type and continuous type events and Li et al. (2011) used a sequence averaged recurrence interval of 100 days to filter out triggered sequences occurring on closely spaced but not overlapping fault patches.

\section{Estimation of slow fault slip from repeating earthquakes} Based on identified repeaters, we can estimate the cumulative slip of repeating earthquakes that tells us about the slow slip history in the area surrounding the repeater patch. There are three types of models that can be used to estimate slip from repeaters.
Nadeau and Johnson (1998) proposed the following empirical relationship between fault creep $(\mathrm{d} ; \mathrm{cm})$ and repeater seismic moment (Mo; dyne.cm) which is also shown in Fig. 9.

$$
d=10^{-2.36} M_{o}^{0.17} \text {. }
$$

They used observed data of the moment release rate of repeaters and an average regional geodetic creep rates in Parkfield and Stone Canyon to build the empirical relationship. The Parkfield repeaters are selected by waveform cross-correlation and visual inspection (Nadeau et al. 1995; Zechar and Nadeau 2012) and the Stone Canyon repeaters are selected by hypocenter locations (Ellsworth and Dietz 1990). This relationship has been used to estimate creep from repeating earthquakes in various areas (Table 1) (Chen et al. 2007; Uchida et al. 2003; Igarashi et al. 2003). Variations in the empirical relationship have been posited as $d=10^{-1.09 \pm 0.2} M_{o}^{0.102 \pm 0.3}$ (Nadeau and McEvilly 2004) who re-estimated the empirical scaling constants for larger sections along the San Andreas fault, and $d=10^{-1.53 \pm 0.37} M_{o}^{0.10 \pm 0.02}$ (Khoshmanesh et al. 2015) who re-estimated constants in the model from high-resolution spatiotemporal modeling of the slip on the San Andreas fault.

The scaling by Nadeau and Johnson (1998) suggests that $T_{r} \propto M_{o}^{1 / 6}$, where $T_{r}$ represents the recurrence interval. This relationship is different from the generally accepted relationship $T_{r} \propto M_{o}^{1 / 3}$ which is derived from the standard assumption of constant stress drop (Nadeau and Johnson 1998) and discussed based on laboratory-derived friction laws 


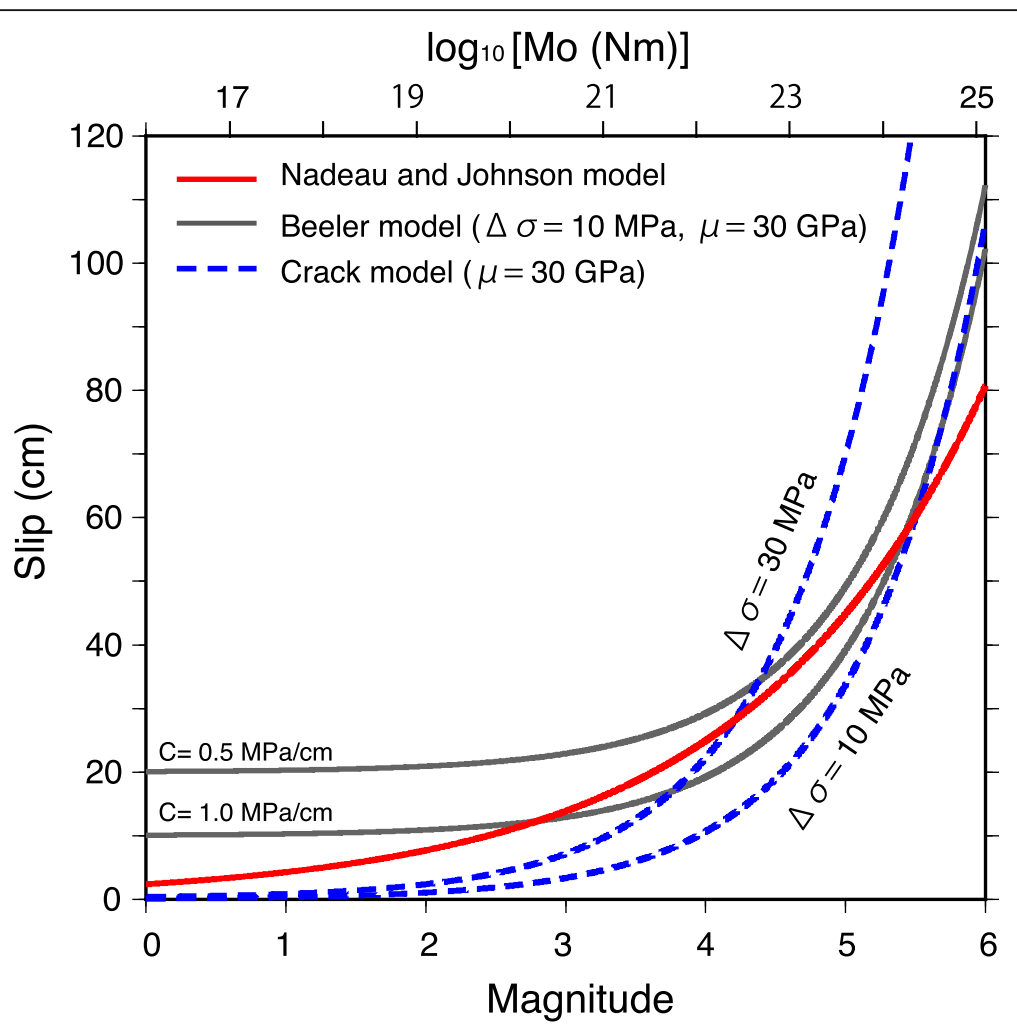

Fig. 9 Relationship between magnitude (moment) and slip for three models (Eqs. 4, 5, and 6). Note that the Beeler model has three additional parameters $(\mu, \Delta \sigma, C)$, and the crack model has two additional parameters $(\mu, \Delta \sigma)$. Rigidity is fixed to $30 \mathrm{GPa}$

(e.g., Chen and Lapusta 2009; Cattania and Segall 2018) and observations (Chen et al. 2007; Yu 2013; Dominguez et al. 2016). Chen et al. (2007) showed that the $T_{r}-M_{o}$ relationship holds not only in California but also in Taiwan and Japan when geodetically derived slip rates are adjusted. The adjustment was done by $T_{r}^{\text {nor }}=T_{r}\left(V_{f} / V_{\text {parkfield }}\right)$, where $T_{r}^{\text {nor }}$ is the normalized recurrence interval, $T_{r}$ and $V_{f}$ are the observed recurrence interval and geodetically derived long-term fault slip rate for different areas and $V_{\text {park- }}$ field $=2.3 \mathrm{~cm} /$ year is the reference loading rate in Parkfield. The $T_{r}-M_{o}$ relationship with additional Japan, Tonga-Kermadec, and Mexico data from following studies also show a mostly consistent $T_{r}-M_{o}$

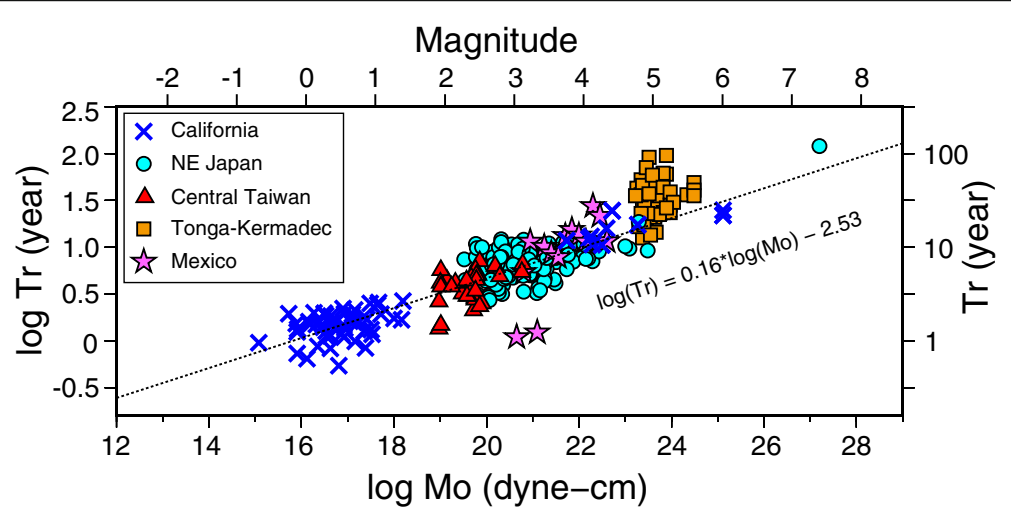

Fig. 10 Comparison of the relationship between the sequence-averaged recurrence interval ( $T r$ ) and seismic moment (Mo) for different study areas. Please note that the recurrence interval is normalized by the ratio of plate convergence rates between California and other regions. The original figures and details can be found in Nadeau and Johnson (1998) (San Andreas fault), Chen et al. (2007) (Central Taiwan), Yu (2013) (TongaKermadec), and Dominguez et al. (2016) (Mexico). For NE Japan, only the data before the Tohoku-oki earthquake and sequences with 8 or more recurrences are selected from the catalog of Uchida and Matsuzawa (2013) 
relationship in world plate-boundary repeaters (Fig. 10). This suggests that Nadeau and Johnson (1998)'s scaling can be applicable in diverse tectonic settings. Please note that the plate boundary slip rate may change in space and time and the Tonga-Kermadec repeaters that have little longer recurrence intervals than expected may be caused by such effect or inaccurate long-term slip rate estimates (Yu 2013).

Another relationship, particularly for repeating earthquakes, proposed by Beeler et al. (2001) is also used to estimate the slip of repeating earthquakes (Mavrommatis et al. 2015). Beeler et al. (2001) considered the contribution of aseismic slip during the earthquake cycle and expressed slip as follows:

$$
d=\Delta \sigma\left[\frac{1}{1.81 \mu}\left(\frac{\overline{M_{o}}}{\Delta \sigma}\right)^{\frac{1}{3}}+\frac{1}{C}\right],
$$

where $\mu$ is rigidity, $\Delta \sigma$ is stress drop and $C$ is the strain hardening coefficient. This amount includes aseismic slip during each earthquake cycle and thus can be used to estimate the total slip amount at a repeater source location. The example of the shape of the function is shown in Fig. 9. Igarashi et al. (2003) and Mavrommatis et al. (2015) suggest that the Nadeau and Johnson (1998) and Beeler et al. (2001) models yield a similar result if the strain hardening coefficient used in Beeler's model is appropriately selected.

Some studies use a standard crack model with a uniform stress drop that is usually assumed for regular earthquakes,

$$
d=\frac{M_{o}}{\pi \mu a^{2}},
$$

where $a$ is the crack radius (see Fig. 9 for the shape of the function). The crack radius can be estimated by assuming or estimating the stress drop $(\Delta \sigma)$ of the earthquake from Eq. (1) (Eshelby 1957). These types of equations are employed in Schmittbuhl et al. (2016) and Yao et al. (2017).

Nadeau and Johnson's relationship (Eq. (4)) and Beeler's relationship (Eq. (5)) are similar for repeater magnitudes in the range $(2.5 \leqq M \leqq 5)$ in Tohoku when appropriate $C$ values $(0.5-1.0 \mathrm{MPa} / \mathrm{cm}$, Igarashi et al. (2001)) are selected (Fig. 9). Beeler's model tends to converge toward the crack model with constant stress drop for large earthquakes but calculates larger slips for smaller earthquakes depending on $C$ (Fig. 9). The standard crack model yields relatively small slip compared with Nadeau and Johnson and Beeler's relationships for small earthquakes $(M<3)$. I do not discuss the performance of these models, but it should be noted that the absolute value of slip estimates from repeating earthquakes depends largely on the selection of model: they differ by more than an order of magnitude although they are dependent on the constants and magnitudes. However, the spatio-temporal patterns derived from these relationships may be similar if the magnitude range of repeater sequences is not large.

\section{Estimating spatio-temporal change of slow slip}

The cumulative slip of a particular repeater sequence provides slow-slip information at one point on the fault but multiple repeaters can be used to understand regional slip and its spatial change. To examine the spatial distribution of slow slip, spatial filtering (averaging) is often used (e.g., Uchida et al. 2003; Nadeau and McEvilly 1999). The spatial filtering also contributes to the robustness of slow slip estimates. Previous study used a 2 $\mathrm{km}$ radius at Parkfield (Nadeau and McEvilly 1999), $0.3^{\circ}$ by $0.3^{\circ}$ window at NE Japan (Uchida et al. 2003) and a 0.15 by $0.15^{\circ}$ window at Chile (Meng et al. 2015) for averaging. Recently, space-time modeling using Bayesian approaches has also been applied to estimate the spatio-temporal distribution of creep in California and Japan (Nomura et al. 2014; Nomura et al. 2017). In this method, both spatial and temporal changes are modeled by spline functions.

\section{Mechanics of slow slip derived from repeating earthquakes}

Interplate slow slip plays an important role in the earthquake cycle and in fault deformation (e.g., Bürgmann 2018; Obara and Kato 2016). Most repeating earthquakes identified in previous studies are located on known creeping sections of plate boundary faults and provide useful insights into the distribution and temporal changes of fault slow slip. In this section, I review the features of slow slip estimates made using repeating earthquakes.

\section{Slow slip in and around the San Andreas fault and other inland creeping faults}

The first estimate of the spatio-temporal distribution of interplate creep based on repeaters was performed on a $\sim 20 \mathrm{~km}$ segment around Parkfield along the San Andreas Fault (Nadeau and McEvilly 1999). They found a slip rate transient from 1988 to 1998 that migrated along the segment. During the period, moderate-sized earthquakes $(4.2 \leq M \leq 5.0)$ also occurred. This work illuminated the importance of repeater data in constraining slow slip at depth. Estimations of fault slow slip rates from repeaters include Bürgmann et al. (2000) who estimated a creep rate of $5-7 \mathrm{~mm} /$ year at $4-10 \mathrm{~km}$ depth along the north Hayward fault, Materna et al. (2018) who showed the easternmost segment of the transform 
Mendocino Fault Zone displays creep at about $65 \%$ of the long-term slip rate, and Rau et al. (2007) who estimated $24.9-77.5 \mathrm{~mm}$ /year slip rates $10-22 \mathrm{~km}$ deep on the northern Longitudinal Valley fault in Taiwan, which are comparable to the GPS-derived slip rates of $47.5 \pm$ $5.8 \mathrm{~mm} /$ year at similar depths. Also, Chen et al. (2008) suggested that along its northern half, the $30-\mathrm{km}$-long Chihshang fault is creeping at a rate of $\sim 3 \mathrm{~cm} /$ year at 7-23 km depth, Schmittbuhl et al. (2016) suggest that fault creep occurs in the Marmara Sea along the north Anatolian fault, and Templeton et al. (2008) estimated cumulative creep on several strike-slip faults in central California over 21 years (Table 1 ).

The time-dependent creep rate estimated from repeating earthquakes helps reveal the dynamic nature of slow fault slip. Nadeau and McEvilly (2004) showed a quasi-periodic occurrence of slow slip accelerations along a $\sim 175-\mathrm{km}$-long section of the central San Andreas fault. The transient events occurred both in conjunction with and independent of transient slip from larger earthquakes. Recently, Turner et al. (2015), revised slip rate fluctuations with additional repeater data (1984-2011) and compared them with InSAR data (Fig. 11). They find that the slip rate fluctuates over $\sim 2$ year periods. The distribution of postseismic slip of major earthquakes is also evident from repeater data. Templeton et al. (2009) examined the distribution of postseismic slip on the Calaveras fault following the
1984 Morgan Hill earthquake (M6.2). They showed repeating earthquakes occur preferentially in areas adjacent to the coseismic rupture and the activity indicates accelerated slip and decay. In the case of the 1989 Loma Prieta earthquake (M6.9), the creep rate on the San Andreas fault adjacent to the coseismic rupture increased dramatically after the earthquake and fell back to its interseismic rate in about 10 years. On the other hand, the nearly subparallel Sargent fault did not show an immediate response (Turner et al. 2013). It is also interesting that the creep of the two faults appears correlated, suggesting a mutual driving force in the system. Other examples of postseismic deformation include the 2004 Parkfield earthquake (Mw6.0) (Khoshmanesh et al. 2015) and a large slow-slip transient following the 1998 earthquake near San Juan Bautista (Mw 5.1) (Taira et al. 2014) on either end of the creeping section of the San Andreas fault. As the fault surface surrounding these two ruptures is generally accommodating slip by fault creep, effective moment release by afterslip appears to have exceeded that of their respective mainshocks.

\section{Slow slip in Japan and other subduction zones}

Repeaters in subduction zones were first found in the northeastern Japan subduction zone. They enabled the estimation of the spatial variation of interplate creep rates beneath the sea (Igarashi et al. 2003; Matsuzawa et al. 2002). The spatial heterogeneity of slow slip in

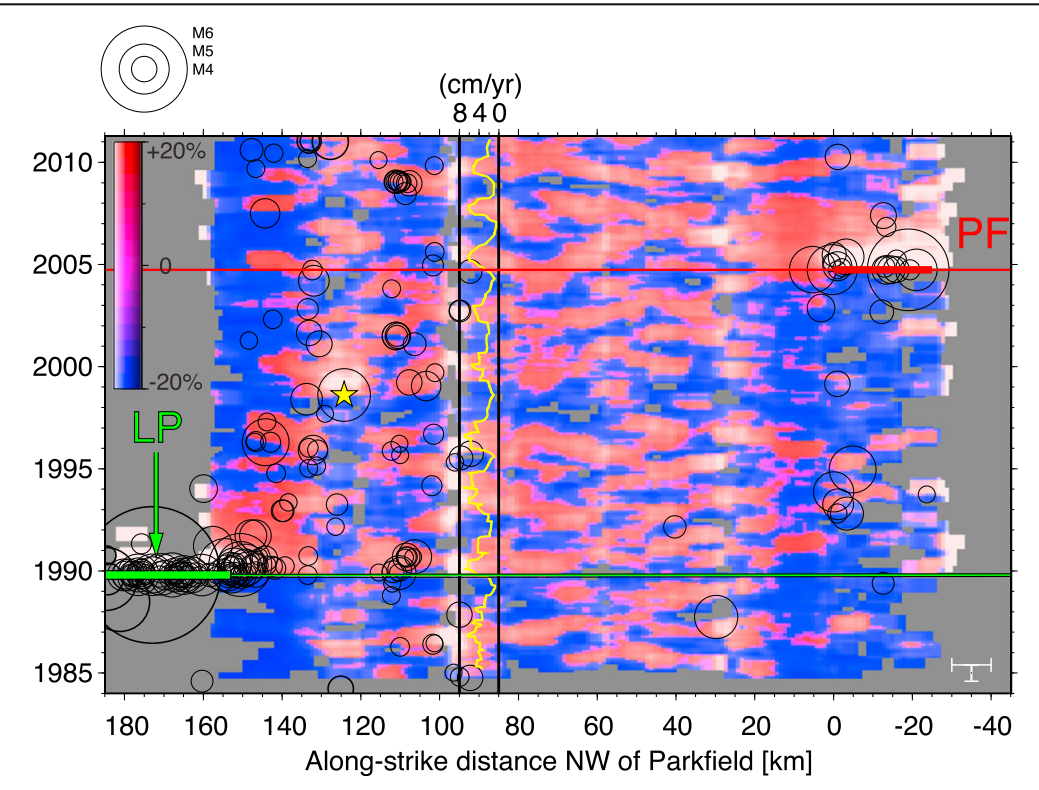

Fig. 11 Periodic slip rate change observed along the San Andreas fault (after Turner et al. (2015)). The slip rate is denoted by color and in percent difference from the average long-term rate. Red and blue indicate slip rates higher or lower than the long-term average. White indicates higher uncertainty associated with fewer repeating earthquake sequences or with rapidly changing rates. White bars at the lower right show the spatial and temporal smoothing windows used. Thick and thin horizontal bars show the rupture extent and timing of The Loma Prieta (LP, in green) and Parkfield (PF, in red) earthquakes. Circles show earthquakes along the fault $(M \geqq 3.5)$ that are scaled along with their magnitude (see scale at top left). The yellow highlighted trace shows the slip rate history (given in absolute terms) in the section from 85 to $95 \mathrm{~km}$ NW of PF 
northeastern Japan also revealed strong coupling and an absence of repeaters in the maximum slip area of the 2011 M9.0 Tohoku-oki earthquake (Uchida and Matsuzawa 2011). Slow slip rates identified using repeaters revealed contrasts in interplate coupling off Kanto and Tohoku, Japan where the overlying plates are different (Philippine Sea plate and Okhotsk plates) (Uchida et al. 2009a). Examples of estimates of spatial changes in subduction creep rate variation include Igarashi (2010) who conducted a systematic search of repeaters around Japan and found variations of slip rate related to past large earthquakes' locations and spatial differences in plate convergence rates. Yamashita et al. (2012) found spatially heterogeneous interplate coupling in the southwestern Japan subduction zone and $\mathrm{Yu}$ (2013) found that interplate coupling is mostly weak along the Tonga-Kermadec-Vanuatu subduction zone except for in the northern section $\left(15^{\circ}-19^{\circ} \mathrm{S}\right)$ of the Tonga arc (Table 1). These estimates of interplate coupling have contributed to the assessment of the potential for megathrust earthquakes.

Temporal changes in slow slip rates in subduction zones revealed that postseismic slip can be resolved for smaller earthquakes than previously observed (e.g., Uchida et al. 2003). Postseismic slip following earthquakes has been observed using repeating earthquakes for many subduction zone earthquakes including the 1994 Sanriku-oki earthquake (M7.6) (Uchida et al. 2004), the 2003 Tokachi-oki earthquake (M8.0) (Matsubara et al. 2005), the 2004 Sumatra earthquake (M9.2) (Yu et al. 2013), the 2005 Nias earthquake (M8.6) (Yu et al. 2013), the 2011 Tohoku-oki earthquake (Mw 9.0) (Uchida and Matsuzawa 2013), and the 2012 Nicoya earthquake (Mw7.6) (Yao et al. 2017) (Table 1). These results provide independent and useful estimations of postseismic slip complementary to those obtained from geodetic data. Figure 12e, f shows an example of variable afterslips of the 2011 Tohoku-oki earthquake that depends on the location on the plate boundary. In general, the regions close to the Tohoku-oki earthquake's rupture area show rapid afterslip (Fig. 12e) while distant places show small or delayed afterslip (Fig. 12f). The rupture area of the Tohoku-oki earthquake shows no afterslip (Fig. 12d). The Tohoku-oki earthquake also speeds up slip on the adjacent plate boundary in the Kanto area (regions 16 and 17 in Fig. 12) where there is a different overlying plate (Philippine Sea plate) than in the source area (Okhotsk plate) (Uchida et al. 2016a). Nomura et al. (2017) studied 13 major earthquakes in the northeastern Japan subduction zone using the same method and obtained a relationship of mainshock magnitude with logarithms of the duration and total moment of postseismic slip. The results show general proportional relationship and illuminated deviations for each event. Matsubara et al. (2005) and Uchida et al. (2009b) studied the afterslip of the 2003 Tokachi-oki earthquake (M8.0) and its migration. They suggest that the migration of afterslip triggered aftershocks and adjacent large earthquakes (Uchida et al. 2009b). In the case of the 2012 Haida Gwaii earthquake in the Queen Charlotte plate boundary zone, the mainshock on the subduction plate interface triggered postseismic slip not only on the subduction thrust but also on the strike-slip fault that accommodates trench-parallel motion of the oblique subduction in the area (Hayward and Bostock 2017).

Quasi-periodic slow slip behavior similar to that observed on the San Andreas fault was also found along a 900-km-long segment along the Japan and Kuril trenches (Uchida et al. 2016b). Its periodicity varied from 1 to 6 years, and slip accelerations often coincided with or preceded clusters of large $(M \geq 5)$ earthquakes, including the 2011 M9 Tohoku-oki earthquake. The swarm-like activity pattern of small repeating earthquakes that emerged before some of the largest earthquakes suggests that spontaneous slow-slip events are involved in the underlying aseismic loading process that drives episodic deformation transients and earthquakes.

Preseismic slow slip has been reported in several areas. Uchida et al. (2004) reported on the slow slip in the 3 days, 1 week, and 8 months before three off-Sanriku, Japan M 7 earthquakes. For the 2011 Tohoku-oki earthquake, the aftershocks of a M7.3 earthquake that occurred 2 days before the mainshock contained many repeating earthquakes suggesting the occurrence of slow slip (Kato et al. 2012; Uchida and Matsuzawa 2013) (Fig. 12a, Fig. 13a). Kato et al. (2012) showed that repeaters are included in the seismicity that migrated twice in the direction of the hypocenter of the mainshock (Fig. 13a). Such indications of slow slip on time scales of days to weeks were also found for the 2014 Iquique earthquake (M8.1) (Kato and Nakagawa 2014; Meng et al. 2015), a $2016 \mathrm{Mw} 6.0$ earthquake in central Italy (Vuan et al. 2017) and the 2017 Valparaiso earthquake in Chile (Ruiz et al. 2017). On the other hand, Mavrommatis et al. (2015) and Uchida and Matsuzawa (2013) showed long-term slip rates increased for several years to a decade around the seismic slip area of the 2011 Tohoku-oki earthquake (Fig. 13b). Since interplate non-steady slow slip produces transient stress increases in the adjacent areas (Mazzotti and Adams 2004; Obara and Kato 2016), it is important to monitor slow slip from repeating earthquakes.

\section{Toward a better use of repeating earthquake data for estimating slow fault slip}

Repeater data provide estimates of slow fault slip that are independent from geodetic data. Comparisons of slow slip based on geodetic data and on repeaters have 


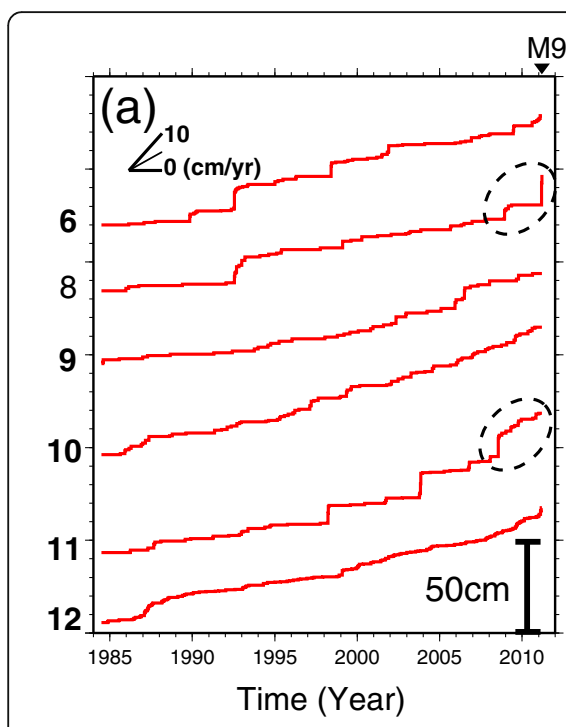

(d)

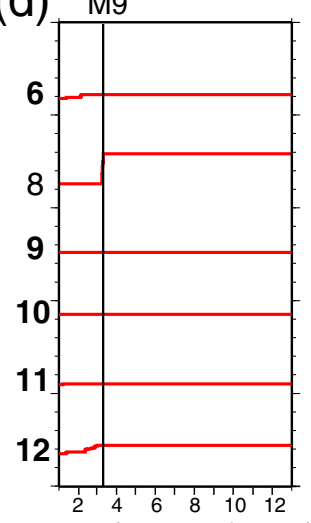

Time (Month of 2011 ) (e)

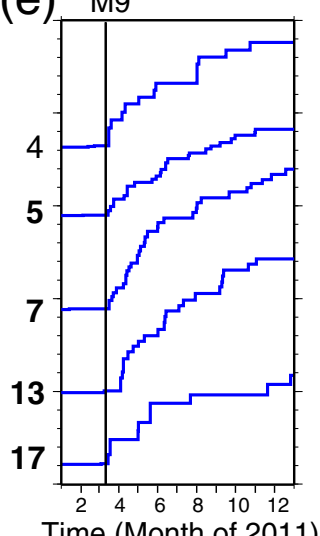

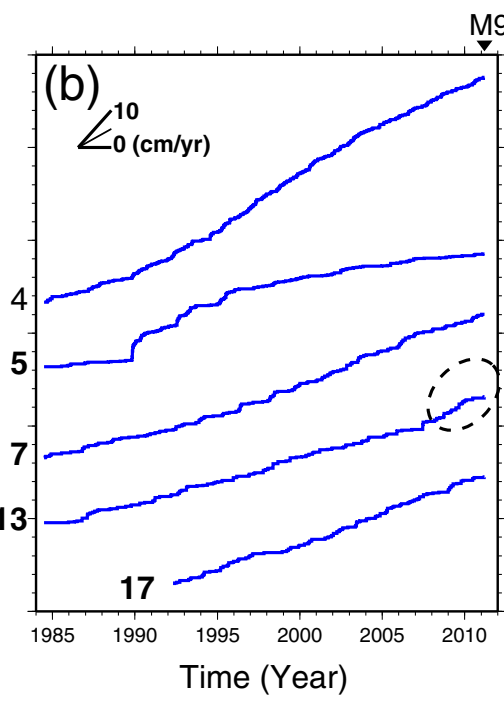

(f) $M 9$

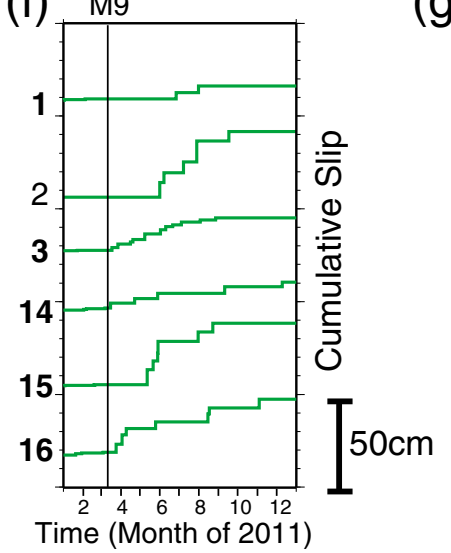

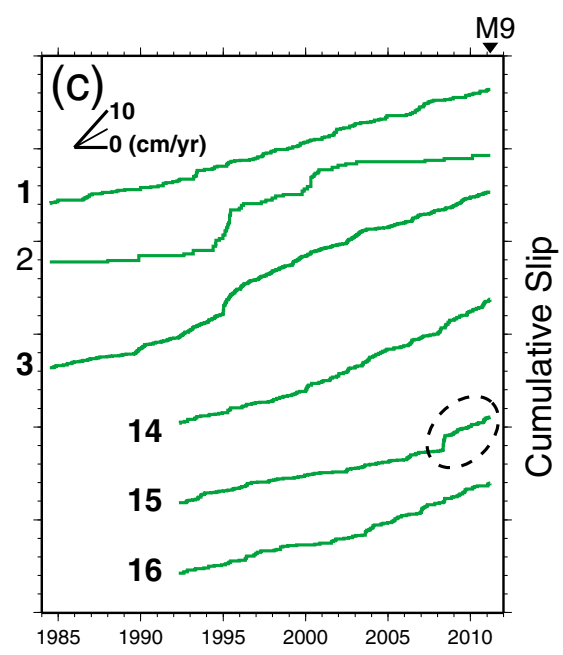

Fig. 12 Temporal evolution of slow slip in sub-regions $\left(0.5^{\circ} \times 0.7^{\circ}\right)$ of the plate interface along the Japan trench (after Uchida and Matsuzawa (2013)). a-c The period before the 2011 Tohoku-oki earthquake. $\mathbf{d}$-f The year that includes the Tohoku-oki earthquake. The regions shown in $\mathbf{g}$ are categorized into areas with coseismic slip from the 2011 event with no afterslip (regions 6, 8, 9, 10, 11, and 12, in red); in the vicinity of the coseismic slip area and showing large, almost immediate slip after the Tohoku-oki earthquake (regions 4, 5, 7, 13, and 17, in blue); and areas distant from the coseismic slip showing small or delayed afterslip (regions 1, 2, 3, 14, 15, and 16). Panels a-f correspond to these categories. In $\mathbf{g}$, contours show the coseismic slip distribution of the Tohoku-oki earthquake (linuma et al. 2012), stars show the epicenters of the 2011 Tohoku-oki earthquake and its two largest interplate aftershocks, and the thick black line shows the northeastern limit of the Philippine Sea plate in the Kanto region (Uchida et al. 2009a). Dashed ellipsoids show slip rate increases before the Tohoku-oki earthquake

been performed in several areas. Along the creeping section of the Hayward-Calaveras fault, repeaters and InSAR-derived slip rates show a consistent spatial patterns (Chaussard et al. 2015) (Fig. 14). Absolute slip rates from the two observations plotted against each other are somewhat scattered but are distributed around the 1 to 1 line (Fig. 14b). In Tohoku, Japan, Fig. 15 demonstrates that the GPS-derived interplate slip deficit rate and the repeater-derived slip rate are anti-correlated for the period before the Tohoku-oki earthquake (Nomura et al. 2017). They also show the coseismic slip area of the 2011 Tohoku-oki earthquake corresponds well with the GPS-derived large slip deficit area and repeater-derived low slip rate area. The comparisons in absolute slip amount also show the correlation but there are significant bias between the repeater-derived and geodetic-derived rates (Fig. 15c). The repeater-derived slip rates in California and Japan are both used the scaling relationship by Nadeau and Johnson (1998), but only the Japanese data show bias with geodetic-derived slip rates. This may imply regional dependency of the scaling law between slip and magnitude.

For afterslip estimations, recent geodetic studies have shown that viscoelastic relaxation after a large earthquake has a significant effect on the postseismic deformation field (e.g., Wang et al. 2012). The effect of poroelastic rebound has also been suggested for large earthquakes (e.g., Peltzer et al. 1996; Hu et al. 2014). 

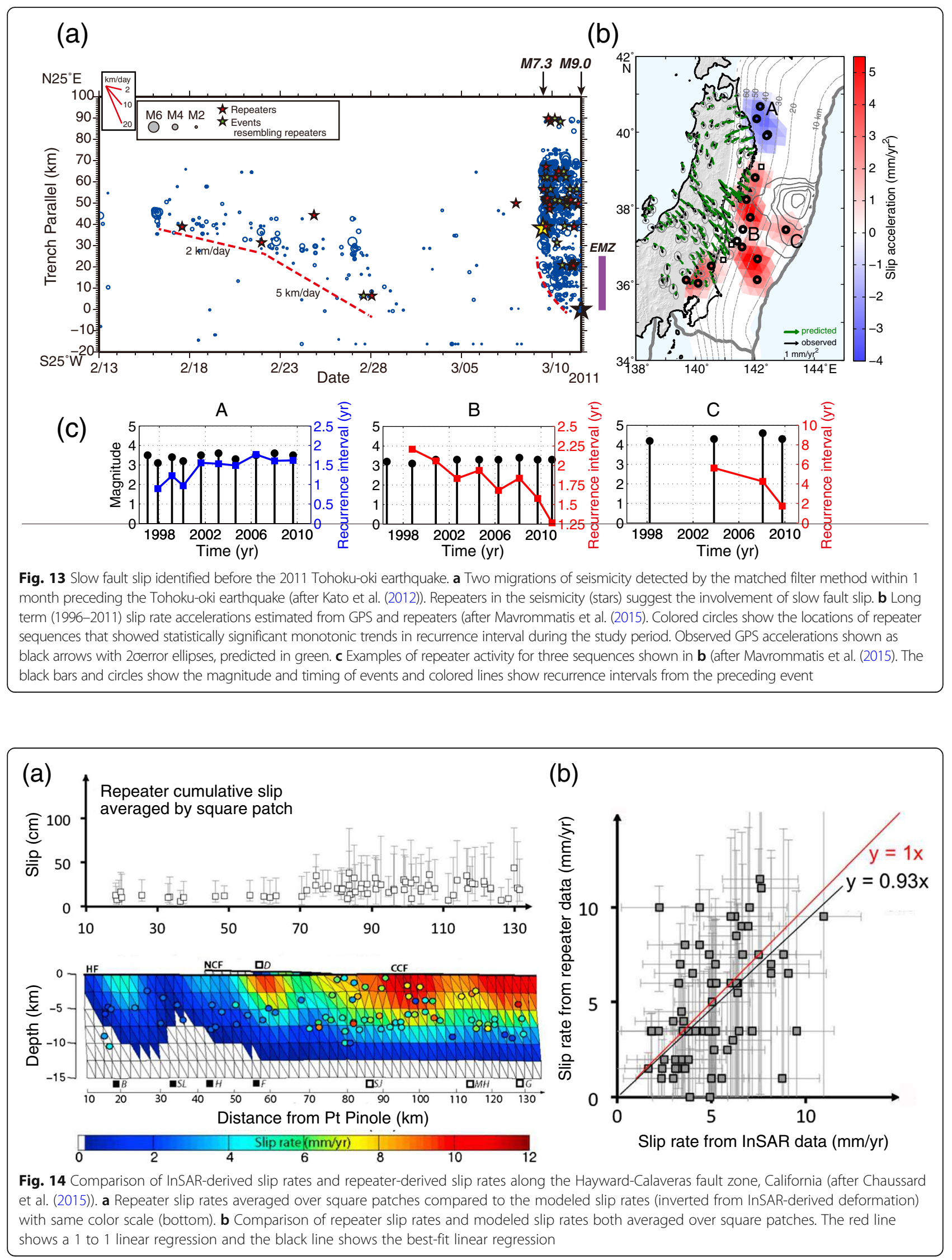


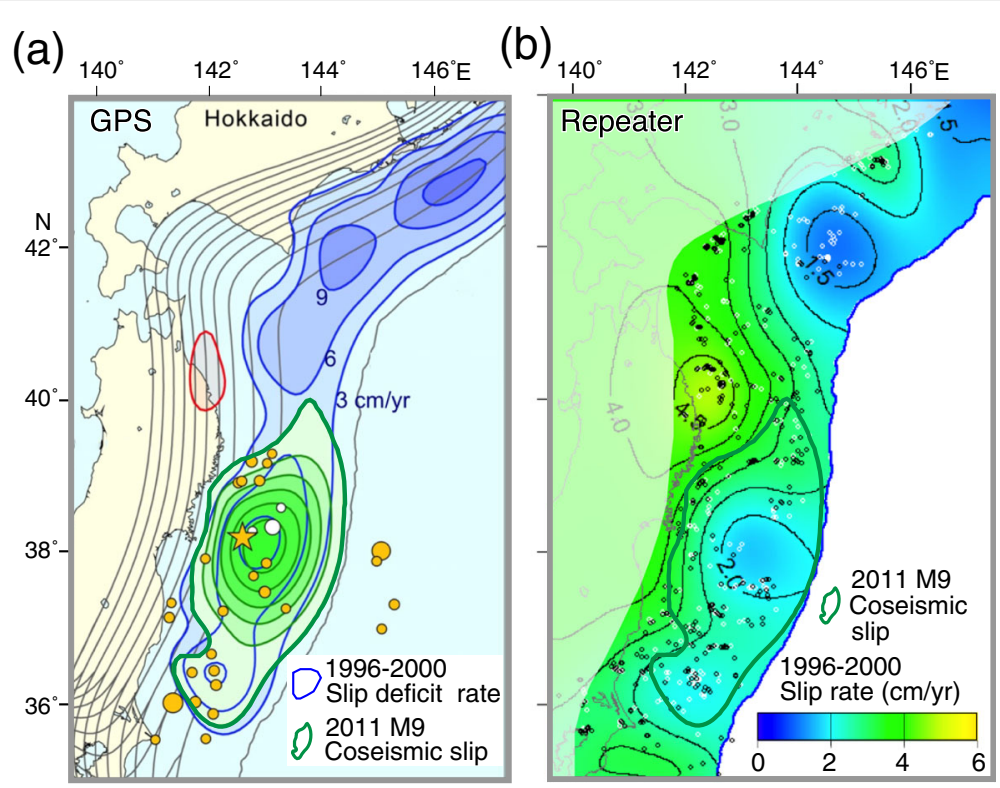

(c)

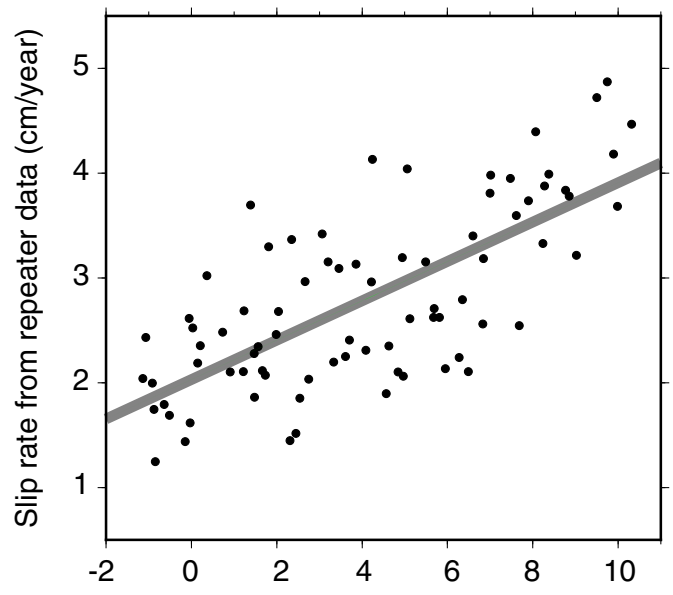

Slip rate from GPS data inversion (cm/year)

Fig. 15 Relationship between slip rate estimated from GPS (Hashimoto et al. 2012) and repeating earthquakes (Nomura et al. 2017) in the Tohoku subduction zone for the period from 1996 to 2000 (modified from Nomura et al. (2017)). a shows the spatial distribution of GPS slip deficit/excess rate by Hashimoto et al. (2012) and $\mathbf{b}$ displays the repeater-derived slip rate for the period of 1996-2000 for comparison. The contour interval for the slip deficit is $3 \mathrm{~cm} /$ year. Green contours in a show the coseismic slip distribution of the 2011 Tohoku-oki earthquake (M9) at a contour interval of $4 \mathrm{~m}$. Orange star shows the epicenter of the Tohoku-oki earthquake. White and orange circles show foreshocks on March 9 and the aftershocks for March 11-14, respectively. The thin black contours represent depth to plates in $10 \mathrm{~km}$ interval. The black and white circles in $\mathbf{b}$ represent repeating earthquakes within and outside the 1996-2000 time period, respectively. The slip rate at 60-km-depth or larger is masked since there are almost no data constraints. Thick green line is $4 \mathrm{~m}$ coseismic slip shown in a. c Slip deficit rates at $\sim 50 \mathrm{~km}$ grid points on the plate interface shallower than $80 \mathrm{~km}$ are sampled and converted to slip rate by assuming a plate convergence rate of $8.5 \mathrm{~cm} / y e a r$. The straight gray line (slope $=0.19$, intercept $=2.0$ ) indicates the least-squares fit to the data

This means that postseismic surface deformation cannot be solely attributed to interplate afterslip. To separate the fault slip and other effects in geodetic data and in mitigating the non-uniqueness of geodetic inversion results, the repeater data are useful since the postseismic slip estimated using repeaters simply denotes interplate slip and is not affected by the other deformation processes mentioned above. An example of such use is by $\mathrm{Hu}$ et al. (2016) who exploited repeating earthquake data to separate shear-zone (plate boundary) deformation and viscoelastic deformation in the surrounding area. They used repeaters to constrain the afterslip on the seismogenic portion of the boundary thrust and model the visco-elastic structure in the Tohoku area based on the GPS-measured postseismic deformation after the 2011 Tohoku-oki earthquake. There have also been studies to use repeaters and geodetic data simultaneously. The simultaneous use of repeating earthquakes and InSAR 
data on the central San Andreas (Khoshmanesh et al. 2015) and Hayward faults (Shirzaei et al. 2013) enabled kinematic modeling of creep pulsing and suggests time-dependent seismic hazards. Mavrommatis et al. (2015) showed that long-term (decadal) slip acceleration occurred around a seismic slip area using both GPS and repeating earthquake data (Fig. 13b).

\section{Conclusions}

Repeating earthquakes that are interpreted to represent recurrent slip on the same seismic patches provide information on fault creep in the surrounding area. Quantifying the degree of waveform similarity and precise hypocenter locations help identify such repeating earthquakes. The method based on hypocenter location can evaluate the source-overlap ratio if the location and source size are accurately estimated. The methods based on waveform similarity have less demands on the number of stations and timing accuracy of the recordings from a seismic network but needs special attention to the frequency range and similarity threshold to eliminate nearby but not overlapping events. For both repeater detection methods, the accurate locations of successive events and the frequency distribution of recurrence intervals of repeater candidates suggest that eliminating triggered events is important in selecting repeating earthquakes and obtaining better estimates of slow slip. Short-recurrence events can be considered as an indicator of triggered nearby events and can be used to refine the detection parameters of repeater candidates. The estimated slow slip or coupling derived from repeating earthquakes have been successful in observing postseismic and interseismic slow slip, including cyclic slow slip accelerations and preseismic unfastening of locked areas. The use of repeating earthquakes as a detector of creep on faults helped illuminate enduring and transient slow fault slip as an important deformation process together with regular earthquakes.

\section{Abbreviations}

CC: Cross-correlation coefficient; Coh: Coherence; GPS: Global Positioning System; InSAR: Interferometric synthetic aperture radar

\footnotetext{
Acknowledgements

I wish to thank Toru Matsuzawa, Akira Hasegawa, and Toshihiro Igarashi for their assistance in developing the repeating earthquake research and discussion. Thanks to Stephen Kirby, Roland Bürgmann, and other co-workers for their collaboration on this topic. The data for Fig. 10 is provided by Kate Chen, Wen-che Yu, and Luis A. Dominguez. The data for Fig. $15 \mathrm{c}$ is provided by Shunichi Nomura. This article was greatly improved due to comments or discussions with Roland Bürgmann, William Ellsworth, two anonymous reviewers, and editor Yuji Yagi. I also wish to thank the Nishida prize review committee and Japan Geoscience Union for their encouragement in writing this manuscript.
}

\section{Funding}

This work was supported by JSPS KAKENHI Grant Numbers 15 K05260 and $17 \mathrm{H} 05309$ and the JSPS Bilateral Joint Research Project "Study on the relationship between slow crustal deformation and earthquake activity based on seismic and geodetic data."

\section{Availability of data and materials}

Data sharing not applicable to this article as no datasets were generated during the current study.

\section{Author's contribution}

NU proposed the topic and constructed the manuscript. The author read and approved the final manuscript.

\section{Competing interests}

The author declares that there are no competing interests.

\section{Publisher's Note}

Springer Nature remains neutral with regard to jurisdictional claims in published maps and institutional affiliations.

Received: 4 January 2019 Accepted: 22 April 2019

Published online: 29 May 2019

\section{References}

Abercrombie RE (1996) The magnitude-frequency distribution of earthquakes recorded with deep seismometers at Cajon Pass, southern California. Tectonophysics 261:1-7

Beeler NM, Lockner DL, Hickman SH (2001) A simple stick-slip and creep-slip model for repeating earthquakes and its implication for microearthquakes at Parkfield. B Seismol Soc Am 91:1797-1804

Bouchon M (1997) The state of stress on some faults of the San Andreas system as inferred from near-field strong motion data. J Geophys Res Solid Earth 102:11731-11744

Bouchon M, Durand V, Marsan D, Karabulut H, Schmittbuhl J (2013) The long precursory phase of most large interplate earthquakes. Nat Geosci 6:299-302

Bouchon M, Karabulut H, Aktar M, Özalaybey S, Schmittbuhl J, Bouin M-P (2011) Extended nucleation of the $1999<$ em $>M</$ em $><$ sub $>$ W $</$ sub $>7.6$ Izmit earthquake. Science 331:877-880

Bürgmann R (2018) The geophysics, geology and mechanics of slow fault slip. Earth Planet Sci Lett 495:112-134

Bürgmann R, Schmidt D, Nadeau RM, d'Alessio M, Fielding E, Manaker D, McEvilly TV, Murray MH (2000) Earthquake potential along the northern Hayward fault, California. Science 289:1178-1182

Cattania C, Segall P (2018) Crack models of repeating earthquakes predict observed moment-recurrence scaling. J Geophys Res Solid Earth 123:476-503

Chaussard E, Bürgmann R, Fattahi H, Johnson CW, Nadeau R, Taira T, Johanson I (2015) Interseismic coupling and refined earthquake potential on the Hayward-Calaveras fault zone. J Geophys Res Solid Earth 120:8570-8590

Chen KH, Bürgmann R, Nadeau RM (2013) Do earthquakes talk to each other? Triggering and interaction of repeating sequences at Parkfield. J Geophys Res Solid Earth 118:165-182

Chen KH, Nadeau RM, Rau RJ (2007) Towards a universal rule on the recurrence interval scaling of repeating earthquakes? Geophys Res Lett 34:L16308

Chen KH, Nadeau RM, Rau R-J (2008) Characteristic repeating earthquakes in an arc-continent collision boundary zone: the Chihshang fault of eastern Taiwan. Earth Planet Sci Lett 276:262-272

Chen T, Lapusta N (2009) Scaling of small repeating earthquakes explained by interaction of seismic and aseismic slip in a rate and state fault model. J Geophys Res 114:B01311

Dominguez LA, Taira Ta, Santoyo MA (2016) Spatiotemporal variations of characteristic repeating earthquake sequences along the middle America trench in Mexico. J Geophys Res Solid Earth 121:8855-8870

Dreger D, Nadeau RM, Chung A (2007) Repeating earthquake finite source models: Strong asperities revealed on the San Andreas Fault. Geophys Res Lett 34:L23302

Ellsworth WL (1995) Characteristic earthquake and long-term earthquake forecasts: implications of Central California seismicity. In: Cheng FY, Sheu MS (eds) Urban Disaster Mitigation: The Role of Science and Technology. Elsevier, Oxford

Ellsworth WL, Bulut F (2018) Nucleation of the 1999 Izmit earthquake by a triggered cascade of foreshocks. Nat Geosci 11:531-535 
Ellsworth WL, Dietz LD (1990) Repeating earthquakes: characteristics and implications. Proc. of workshop XLVI, the 7th U.S.-Japan seminar on earthquake prediction, U.S. GeoL Surv. Open-File Rept 90-98:226-245

Eshelby JD (1957) The determination of the elastic field of an ellipsoidal inclusion, and related problems. Proc R Soc Lon Ser-A 241:376-396

Gardonio B, Marsan D, Lengliné O, Enescu B, Bouchon M, Got J-L (2015) Changes in seismicity and stress loading on subduction faults in the Kanto region, Japan, 2011-2014. J Geophys Res Solid Earth 120. https://doi.org/10.1002/ 2014JB011798

Geller R, Mueller C (1980) Four similar earthquakes in Central California. Geophys Res Lett 7:821-824

Gibbons SJ, Ringdal F (2006) The detection of low magnitude seismic events using array-based waveform correlation. Geophys J Int 165:149-166

Hamaguchi H, Hasegawa A (1975) Recurrent occurrence of the earthquakes with similar wave forms and its related problems. Zisin 28:153-169

Hanks TC, Kanamori H (1979) A moment magnitude scale. J Geophys Res 84: 2348-2350

Hashimoto C, Noda A, Matsuura M (2012) The M w 9.0 Northeast Japan earthquake: total rupture of a basement asperity. Geophys J Int 189:1-5

Hatakeyama N, Uchida N, Matsuzawa T, Nakamura W (2017) Emergence and disappearance of interplate repeating earthquakes following the 2011 M9.0 Tohoku-oki earthquake: slip behavior transition between seismic and aseismic depending on the loading rate. J Geophys Res Solid Earth 122: $5160-5180$

Hatakeyama N, Uchida N, Matsuzawa T, Okada T, Nakajima J, Matsushima T, Kono T, Hirahara S, Nakayama T (2016) Variation in high-frequency wave radiation from small repeating earthquakes as revealed by cross-spectral analysis. Geophys J Int 207:1030-1048

Hayward TW, Bostock MG (2017) Slip behavior of the queen Charlotte plate boundary before and after the 2012, MW 7.8 Haida Gwaii earthquake: evidence from repeating earthquakes. J Geophys Res Solid Earth 122:89909011

Hu Y, Bürgmann R, Freymueller JT, Banerjee P, Wang K (2014) Contributions of poroelastic rebound and a weak volcanic arc to the postseismic deformation of the 2011 Tohoku earthquake. Earth Planets Space 66:106

Hu Y, Bürgmann R, Uchida N, Banerjee P, Freymueller JT (2016) Stress-driven relaxation of heterogeneous upper mantle and time-dependent afterslip following the 2011 Tohoku earthquake. J Geophys Res Solid Earth 121: 2015JB012508

Igarashi T (2010) Spatial changes of inter-plate coupling inferred from sequences of small repeating earthquakes in Japan. Geophys Res Lett 37:L20304

Igarashi T, Matsuzawa T, Hasegawa A (2003) Repeating earthquakes and interplate aseismic slip in the northeastern Japan subduction zone. J Geophys Res 108. https://doi.org/10.1029/2002JB001920

Igarashi T, Matsuzawa T, Umino N, Hasegawa A (2001) Spatial distribution of focal mechanisms for interplate and intraplate earthquakes associated with the subducting Pacific plate beneath the northeastern Japan arc: a triple-plated deep seismic zone. J Geophys Res 106:2177-2191

linuma T, Hino R, Kido M, Inazu D, Osada Y, Ito Y, Ohzono M, Tsushima H, Suzuki S, Fujimoto H, Miura S (2012) Coseismic slip distribution of the 2011 off the Pacific Coast of Tohoku Earthquake (M9.0) refined by means of seafloor geodetic data. J Geophys Res 117:B07409

Imanishi K, Ellsworth WL, Prejean SG (2004) Earthquake source parameters determined by the SAFOD Pilot Hole seismic array. Geophys Res Lett 31: L12S09

Kato A, Nakagawa S (2014) Multiple slow-slip events during a foreshock sequence of the 2014 lquique, Chile mw 8.1 earthquake. Geophys Res Lett 41:5420-5427

Kato A, Obara K, Igarashi T, Tsuruoka H, Nakagawa S, Hirata N (2012) Propagation of slow slip leading up to the 2011 mw 9.0 Tohoku-Oki earthquake. Science 335:705-708

Khoshmanesh M, Shirzaei M, Nadeau RM (2015) Time-dependent model of aseismic slip on the central San Andreas Fault from InSAR time series and repeating earthquakes. J Geophys Res Solid Earth 120: 2015JB012039

Kim A, Dreger DS, Taira Ta, Nadeau RM (2016) Changes in repeating earthquake slip behavior following the 2004 Parkfield main shock from waveform empirical Green's functions finite-source inversion. J Geophys Res Solid Earth 121:1910-1926

Kimura H, Kasahara K, Igarashi T, Hirata N (2006) Repeating earthquake activities associated with the Philippine Sea plate subduction in the Kanto district,
Central Japan: a new plate configuration revealed by interplate aseismic slips. Tectonophysics 417:101-118

Lengliné O, Lamourette L, Vivin L, Cuenot N, Schmittbuhl J (2014) Fluid-induced earthquakes with variable stress drop. J Geophys Res Solid Earth 119:8900-8913

Lengliné O, Marsan D (2009) Inferring the coseismic and postseismic stress changes caused by the $2004 \mathrm{Mw}=6$ Parkfield earthquake from variations of recurrence times of microearthquakes. J Geophys Res Solid Earth 114:B10303

Li L, Chen Q-F, Niu F, Su J (2011) Deep slip rates along the Longmen Shan fault zone estimated from repeating microearthquakes. J Geophys Res Solid Earth 116: B09310

Materna K, Taira Ta, Bürgmann R (2018) Aseismic transform fault slip at the Mendocino triple junction from characteristically repeating earthquakes. Geophys Res Lett 45:699-707

Matsubara M, Yagi Y, Obara K (2005) Plate boundary slip associated with the 2003 off-Tokachi earthquake based on small repeating earthquake data. Geophys Res Lett 32:L08316

Matsuzawa T, Igarashi T, Hasegawa A (2002) Characteristic small-earthquake sequence off Sanriku, northeastern Honshu. Japan Geophys Res Lett 29. https://doi.org/10.1029/2001GL014632

Mavrommatis AP, Segall P, Uchida N, Johnson KM (2015) Long-term acceleration of aseismic slip preceding the Mw 9 Tohoku-oki earthquake: Constraints from repeating earthquakes. Geophys Res Let. https://doi.org/10.1002/ 2015GL066069

Mazzotti Sp, Adams J (2004) Variability of near-term probability for the next great earthquake on the Cascadia subduction zone. B Seismol Soc Am 94:1954-1959

McEvilly TV, Casaday KB (1967) The earthquake sequence of September, 1965 near Antioch, California. B Seismol Soc Am 57:113-124

McLaskey GC, Thomas AM, Glaser SD, Nadeau RM (2012) Fault healing promotes high-frequency earthquakes in laboratory experiments and on natural faults. Nature 491:101-104

Meng L, Huang H, Bürgmann R, Ampuero JP, Strader A (2015) Dual megathrust slip behaviors of the 2014 Iquique earthquake sequence. Earth Planet Sci Lett 411:177-187

Menke W (1999) Using waveform similarity to constrain earthquake locations. B Seismol Soc Am 89:1143-1146

Murray J, Langbein J (2006) Slip on the San Andreas fault at Parkfield, California, over two earthquake cycles, and the implications for seismic Hazard. Bull Seismol Soc Am 96:S283-S303

Nadeau RM, Foxall W, McEvilly TV (1995) Clustering and periodic recurrence of microearthquakes on the San Andreas fault at Parkfield, California. Science 267:503-507

Nadeau RM, Johnson LR (1998) Seismological studies at Parkfield Vl: moment release rates and estimates of source parameters for small repeating earthquakes. B Seismol Soc Am 88:790-814

Nadeau RM, McEvilly TV (1999) Fault slip rates at depth from recurrence intervals of repeating microearthquakes. Science $285: 718-721$

Nadeau RM, McEvilly TV (2004) Periodic pulsing of characteristic microearthquakes on the San Andreas fault. Science 303:220-222

Nakahara H (2004) Correlation distance of waveforms for closely located events-I. implication of the heterogeneous structure around the source region of the 1995 Hyogo-ken Nanbu, Japan, earthquake ( $m w=6.9$ ). Geophys J Int 157:1255-1268

Nomura S, Ogata Y, Nadeau RM (2014) Space-time model for repeating earthquakes and analysis of recurrence intervals on the San Andreas fault near Parkfield, California. J Geophys Res Solid Earth 119:7092-7122

Nomura S, Ogata Y, Uchida N, Matsu'ura M (2017) Spatiotemporal variations of interplate slip rates in Northeast Japan inverted from recurrence intervals of repeating earthquakes. Geophys J Int 208:468-481

Obara K, Kato A (2016) Connecting slow earthquakes to huge earthquakes. Science 353:253-257

Okada T, Matsuzawa T, Hasegawa A (2003) Comparison of source areas of M4.8+-0.1 earthquakes off Kamaishi, NE Japan-are asperities persistent feature? Earth planet. Sci Lett 213:361-374

Omori F (1905) Horizontal pendulum observations of earthquakes in Tokyo : similarity of the seismic motion originating at neighbouring centres. Publ Earthq Invest Commit Foreign Lang 21:9-102

Peltzer G, Rosen P, Rogez F, Hudnut K (1996) Postseismic rebound in fault stepovers caused by pore fluid flow. Science 273:1202-1204

Peng Z, Ben-Zion Y (2005) Spatiotemporal variations of crustal anisotropy from similar events in aftershocks of the 1999 M7.4 Izmit and M7.1 Düzce, Turkey, earthquake sequences. Geophys J Int 160:1027-1043 
Poupinet G, Ellsworth WL, Frechet J (1984) Monitoring velocity variations in the crust using earthquake doublets: an application to the Calaveras fault, California. J Geophys Res 89:5719-5731

Press WH, Teukolsky SA, Vetterling WT, Flannery BP (2007) Numerical recipes 3rd edition: The art of scientific computing. Edn, Vol. Cambridge University Press, Cambridge

Rau R-J, Chen KH, Ching K-E (2007) Repeating earthquakes and seismic potential along the northern Longitudinal Valley fault of eastern Taiwan. Geophys Res Lett 34:L24301

Romesburg C (2004) Cluster analysis for researchers. Edn, Vol. Lulu. Com, North California

Rubin AM, Gillard D, Got J-L (1999) Streaks of microearthquakes along creeping faults. Nature 400:635

Ruiz S, Aden-Antoniow F, Baez JC, Otarola C, Potin B, Campo F, Poli P, Flores C, Satriano C, Leyton F, Madariaga R, Bernard P (2017) Nucleation Phase and Dynamic Inversion of the Mw 6.9 Valparaíso 2017 Earthquake in Central Chile. Geophys Res Lett 44:10,290-210,297

Sato T, Hirasawa T (1973) Body wave spectra from propagating shear cracks. J Phys Earth 21:415-431

Schaff DP, Bokelmann GH, Ellsworth WL, Zanzerkia E, Waldhauser F, Beroza GC (2004) Optimizing correlation techniques for improved earthquake location. B Seismol Soc Am 94:705-721

Schmittbuhl J, Karabulut H, Lengliné O, Bouchon M (2016) Long-lasting seismic repeaters in the Central Basin of the Main Marmara fault. Geophys Res Lett 43:9527-9534

Shelly DR, Beroza GC, Ide S (2007) Non-volcanic tremor and low-frequency earthquake swarms. Nature 446:305

Shimamura K, Matsuzawa T, Okada T, Uchida N, Kono T, Hasegawa A (2011) Similarities and differences in the rupture process of the M 4.8 repeatingearthquake sequence off Kamaishi, Northeast Japan: comparison between the 2001 and 2008 events. B Seismol Soc Am 101:2355-2368

Shirzaei M, Bürgmann R, Taira Ta (2013) Implications of recent asperity failures and aseismic creep for time-dependent earthquake hazard on the Hayward fault. Earth Planet Sci Lett 371-372:59-66

Taira TA, Bürgmann R, Nadeau RM, Dreger DS (2014) Variability of fault slip behavior along the San Andreas Fault in the San Juan Bautista Region. J Geophys Res Solid Earth. https://doi.org/10.1002/2014JB011427

Templeton DC, Nadeau RM, Bürgmann R (2008) Behavior of repeating earthquake sequences in Central California and the implications for subsurface fault creep. B Seismol Soc Am 98:52-65

Templeton DC, Nadeau RM, Bürgmann R (2009) Distribution of postseismic slip on the Calaveras fault, California, following the 1984 M6.2 Morgan Hill earthquake. Earth Planet Sci Lett 277:1-8

Turner RC, Nadeau RM, Bürgmann R (2013) Aseismic slip and fault interaction from repeating earthquakes in the Loma Prieta aftershock zone. Geophys Res Lett 40:1079-1083

Turner RC, Shirzaei M, Nadeau RM, Bürgmann R (2015) Slow and Go: Pulsing slip rates on the creeping section of the San Andreas Fault. J Geophys Res Solid Earth 120. https://doi.org/10.1002/2015JB011998

Uchida N, Asano Y, Hasegawa A (2016a) Acceleration of regional plate subduction beneath Kanto, Japan, after the 2011 Tohoku-oki earthquake. Geophys Res Lett 43:9002-9008

Uchida, N. , Bürgmann, R. (2019) Repeating earthquakes. Annual Review of Earth and Planetary Sciences 47: https://doi.org/10.1146/annurev-earth-053018060119, in press

Uchida N, Hasegawa A, Matsuzawa T, Igarashi T (2004) Pre- and post-seismic slip on the plate boundary off Sanriku, NE Japan associated with three interplate earthquakes as estimated from small repeating earthquake data. Tectonophysics 385:1-15

Uchida N, linuma T, Nadeau RM, Bürgmann R, Hino R (2016b) Periodic slow slip triggers megathrust zone earthquakes in northeastern Japan. Science 351:488-492

Uchida N, Matsuzawa T (2011) Coupling coefficient, hierarchical structure, and earthquake cycle for the source area of the 2011 off the Pacific coast of Tohoku earthquake inferred from small repeating earthquake data. Earth Planets Space 63:675-679

Uchida N, Matsuzawa T (2013) Pre- and postseismic slow slip surrounding the 2011 Tohoku-oki earthquake rupture. Earth Planet Sci Lett 374:81-91

Uchida N, Matsuzawa T, Ellsworth WL, Imanishi K, Shimamura K, Hasegawa A (2012) Source parameters of microearthquakes on an interplate asperity off Kamaishi, NE Japan over two earthquake cycles. Geophys J Int 189:999-1014
Uchida N, Matsuzawa T, Hirahara S, Hasegawa A, Kasahara M (2006) Monitoring of interplate quasi-static slip alog the Kuril and Japan trenches using repeating earthquake data. Chikyu 28:463-469

Uchida N, Matsuzawa T, Igarashi T, Hasegawa A (2003) Interplate quasi-static slip off Sanriku, NE Japan, estimated from repeating earthquakes. Geophys Res Lett 30. https://doi.org/10.1029/2003GL017452

Uchida N, Nakajima J, Hasegawa A, Matsuzawa T (2009a) What controls interplate coupling?: evidence for abrupt change in coupling across a border between two overlying plates in the NE Japan subduction zone. Earth Planet Sci Lett 283:111-121

Uchida N, Yui S, Miura S, Matsuzawa T, Hasegawa A, Motoya Y, Kasahara M (2009b) Quasi-static slip on the plate boundary associated with the 2003 M8. 0 Tokachi-oki and 2004 M7.1 off-Kushiro earthquakes, Japan. Gondwana Res 16:527-533

Vidale JE, Ellsworth WL, Cole A, Marone C (1994) Variations in rupture process with recurrence interval in a repeated small earthquake. Nature 368:624

Vuan A, Sugan M, Chiaraluce L, Di Stefano R (2017) Loading rate variations along a Midcrustal shear zone preceding the Mw6.0 earthquake of 24 august 2016 in Central Italy. Geophys Res Lett 44(12):170-112,180

Waldhauser F, Ellsworth WL (2000) A double-difference earthquake location algorithm: method and application to the northern Hayward fault, California. B Seismol Soc Am 90:1353-1368

Waldhauser F, Ellsworth WL (2002) Fault structure and mechanics of the Hayward Fault, California, from double-difference earthquake locations. J Geophys Res Solid Earth 107:ESE 3-1-ESE 3-15

Waldhauser F, Ellsworth WL, Schaff DP, Cole A (2004) Streaks, multiplets, and holes: high-resolution spatio-temporal behavior of Parkfield seismicity. Geophys Res Lett 31:L18608

Waldhauser F, Schaff DP (2008) Large-scale relocation of two decades of northern California seismicity using cross-correlation and double-difference methods. J Geophys Res Solid Earth 113:B08311

Wang K, Hu Y, He J (2012) Deformation cycles of subduction earthquakes in a viscoelastic earth. Nature 484:327

Yamashita Y, Shimizu H, Goto K (2012) Small repeating earthquake activity, interplate quasi-static slip, and interplate coupling in the Hyuga-nada, southwestern Japan subduction zone. Geophys Res Lett 39:L08304

Yao D, Walter Jl, Meng X, Hobbs TE, Peng Z, Newman AV, Schwartz SY, Protti M (2017) Detailed spatiotemporal evolution of microseismicity and repeating earthquakes following the 2012 mw 7.6 Nicoya earthquake. J Geophys Res Solid Earth 122:524-542

Yu WC (2013) Shallow-focus repeating earthquakes in the Tonga-KermadecVanuatu subduction zones. B Seismol Soc Am 103:463-486

Yu WC, Song TRA, Silver PG (2013) Repeating aftershocks of the great 2004 Sumatra and 2005 Nias earthquakes. J Asian Earth Sci 67-68:153-170

Zechar JD, Nadeau RM (2012) Predictability of repeating earthquakes near Parkfield, California. Geophys J Int 190:457-462

\section{Submit your manuscript to a SpringerOpen ${ }^{\circ}$ journal and benefit from:}

- Convenient online submission

- Rigorous peer review

- Open access: articles freely available online

- High visibility within the field

- Retaining the copyright to your article

Submit your next manuscript at $>$ springeropen.com 